\title{
The Application of Total Quality Management in Palestinian and Lebanese Universities from the Perspective of Faculty Members
}

\author{
Ali Lutfe Ali Qashmar \\ Psychology - Humanities \\ Al-Istqlal University - Palestine \\ alilutfe@gmail.com
}

\author{
Hadia Abdel Rahim Hammoud \\ Vocational education - Aldose walking \\ Akkar - Lebanon \\ hadyahammoud@gmail.com
}

\author{
Samira Ali Arabs \\ Vocational education - Seer walking \\ Tripoli - Lebanon \\ samar.arbesd@gmail.com
}

Accepted 23/9/2019

Received 27/8/2019

\section{Abstract:}

The attention to total quality began during the last two decades of the last century. The problem of the study is determined in the following questions:

- What is the extent of applying TQM in Palestinian and Lebanese universities from the perspective of faculty members?

- Does the extent of the application of total quality management in the Palestinian and Lebanese universities vary according to the following variables: scientific rank, the college in which the faculty member works, and experience?

A random sample of faculty members is selected in Palestinian and Lebanese universities, where the size of the sample is (153) faculty members during the first academic year (2018/2019), and it is selected using a simple random sample. The study concludes that the application of total quality management in Palestinian and Lebanese universities is very high on the first dimension, where the level of response is $82 \%$, and it is high on dimensions $(2,3)$ as it achieved $(70 \%$ to $79 \%)$. The overall response rate is high in terms of percentage (78\%).

The study concludes with a set of recommendations, the most important of which is that the top management in the Palestinian and Lebanese universities should sponsor the application of total quality management, and adopt the incentive system for university employees.

Keywords: Total Quality Management, Palestinian Universities, Faculty Members, Lebanese Universities. 


\section{تطبيق إدارة الجودة الثاملة في الجامعات القلسطينية واللبنانية من وجهة نظر أعضاء هيئة التدريس}

\author{
سمبرة علي عربس \\ تعليم مهني - مهنية سير عابر

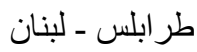

Samar.arbesd@gmail.com

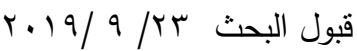

$$
\begin{aligned}
& \text { هاديا عبد الرحيم حمود } \\
& \text { تعليم مهني - مهنية الدوسة } \\
& \text { عكار - لبنان }
\end{aligned}
$$

Hadyahammoud@gmail.com

\author{
علي لطفي علي قشمر \\ علم النفس ـ العلوم الانسانية \\ جامعة الاستقلال ـ فلسطين الانسئ \\ alilutfe@gmail.com
}

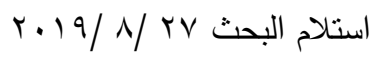

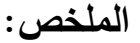

بدأ الاهتمام بمفهوم الجودة الثاملة خلال العقدين الأخيرين من القرن المنصرم، حيث أخذ بمبادئها وتوجهاتها الكثير من المؤسسات

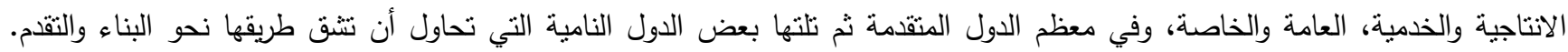
وتتحدد مشكلة الدراسة في التساؤلات التالية:

- - ما مدى تطبيق إدارة الجودة الثناملة في الجامعات الفلسطينية واللبنانية من وجهة نظر أعضاء هيئة التدريس؟

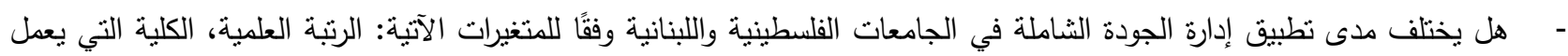
بها عضو هيئة التدريس، سنوات الخبرة؟ وتم اختيار عينة عشوائية من أعضاء هيئة التدريس في الجامعات الفلسطينية واللبنانية، حيث كان حجم العبنة (بهات (10) عضو هبئة تدريس

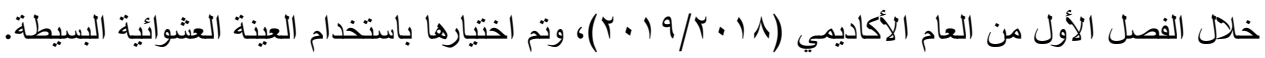

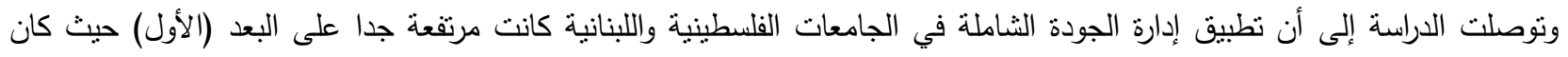

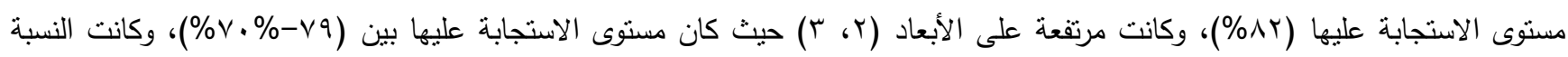

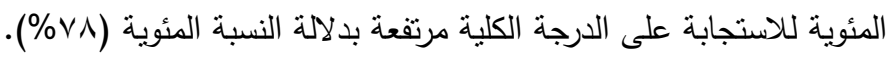

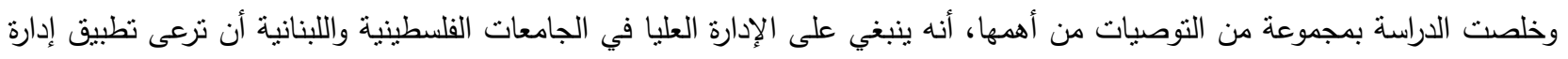
الجودة الثاملة حق الرعاية. اعتماد نظام الحوافز للموظفين في الجامعة. الكلمات المفتاحية: إدارة الجودة الثاملة، الجامعات الفلسطينية، أعضاء هيئة التدريس، الجامعات اللبنانية.

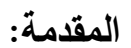

كانت هناك جملة من العوامل التي دفعت باتجاه الأخذ بأفكار

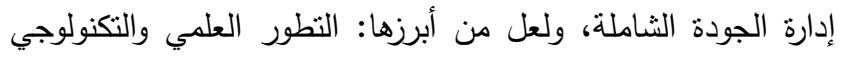

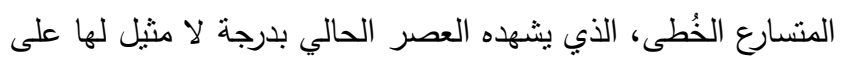

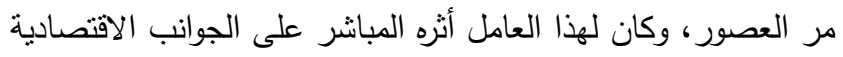

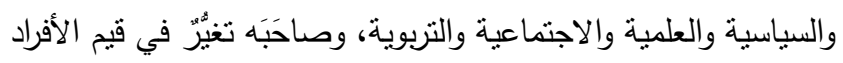

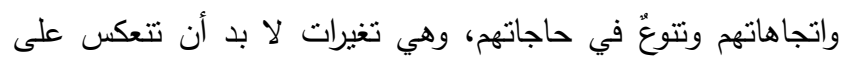

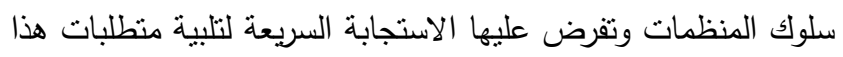

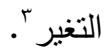
بدأ مفهوم إدارة الجودة الثاملة بالظهور في الثمانينات من القرن العشرين في اليابان حيث يتضمن هذا المفهوم جودة العمليات
إن الانسان يظل دائما يقترع أبواب المعرفة ولكنه لا يمتلك

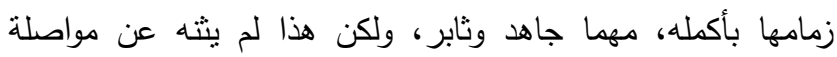

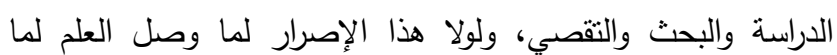
وصل إليه اليوم' . بدأ الاهتمام المطرد بإدارة الجودة الثاملة خلال العقدين

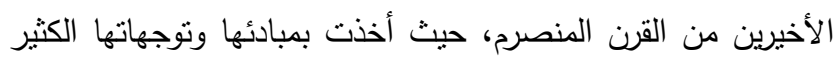

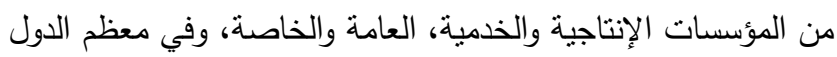

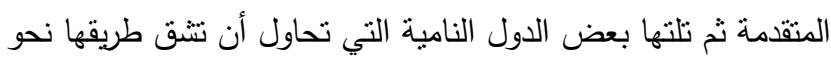


تطبيق إدارة الجودة الثاملة في الجامعات الفلسطينية واللبنانية من وجهة نظر أعضاء هيئة التدريس.

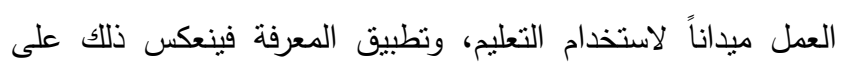

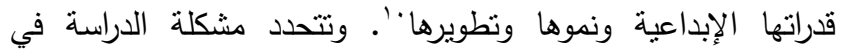

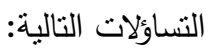

ما مدى نطبيق إدارة الجودة الثاملة في الجامعات الفلسطينية واللبنانية من وجهة نظر أعضاء هيئة التدريس؟

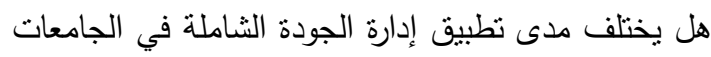
الفلسطينية واللبنانية وفقًا للمتغيرات الآتية: الرتبة العلمية،

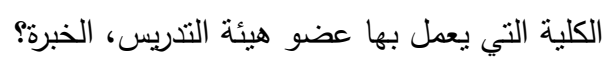

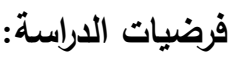

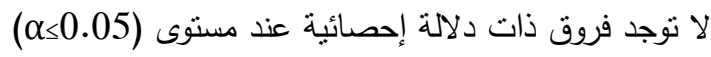

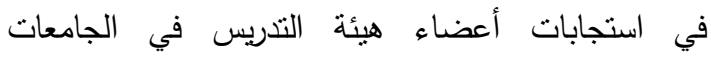
الفلسطينية واللبنانية نُعزى إلى اختلاف الرنبة العلمية.

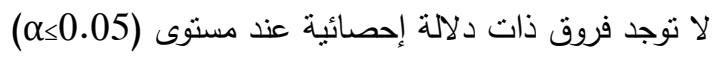

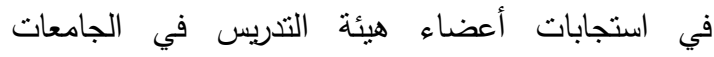
الفلسطينية واللبنانية تُعزى إلى اختلاف الكلية التي يعمل بها

$$
\text { عضو هيئة التدريس. }
$$

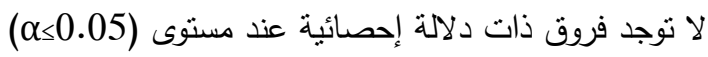
في متوسطات إجابات عينة أفراد الدراسة بالنسبة لأثر دالثر تطبيق إدارة الجودة الثناملة في الجامعات الفلسطينة الفينة واللبنانية تُعزى إلى متغير عدد سنوات الخبرة.

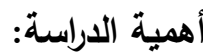

تتثل أهمية هذه الدراسة باعنبارها من أوائل الدراسات التي

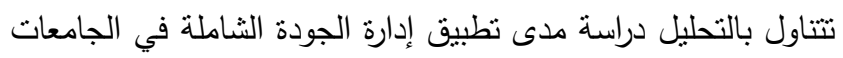
الفلسطينية واللبنانية من وجهة نظر أعضاء هيئة الندريس، حيث إنَّ

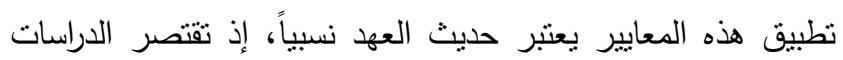

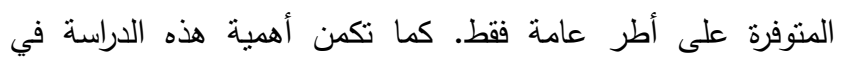
الوقوف على النقاط التي قد بصعب على أعضاء هيئة التدريس

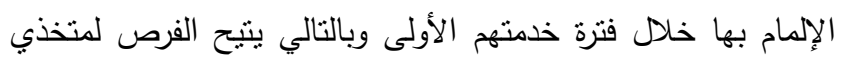
القرار في الجامعة لتوجيه أنشطة تطوير أعضاء هيئة التدريس إليها،

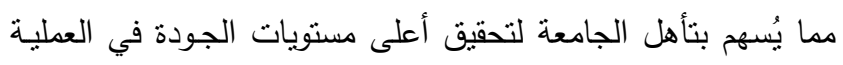
التعليمية، وأخيرًا يُسهم البحث بتوفير بيانات ذات دلاتلة لهئلة لهيئة الاعتماد

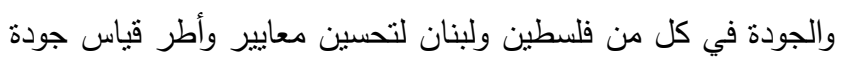

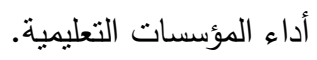

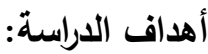

تهذف الدراسـة إلى تسليط الضوء على أثر كلٍّ من الرتبة

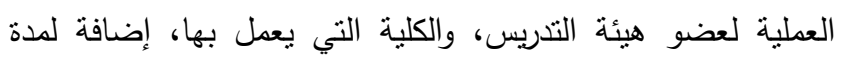

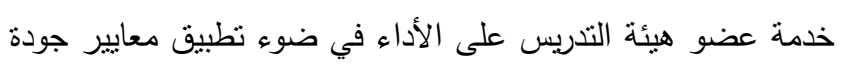
التعليم في كل من فلسطين ولبنان من خلال تحليل هذه العلاقة. ويمكن تحقيق ذلك من خلال الأهداف الفرعية التالية:
بالإضافة الى جودة المنتج ويركز على العمل الجماعي ويشجع مشاركة العاملين واندماجهم، بالإضافة إلى التزكيز على العملاء

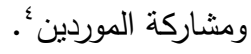

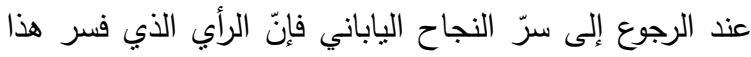

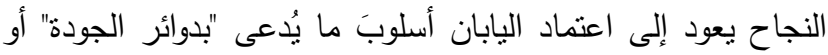
"رقابة الجودة " الني كان هدفها مناقثة سبل تحسين المنتجات وجودة عملياتها. ويتم ذلك من خلال تحفيز العاملين على تحديد المشكلات المحتملة للجودة ثم عرض الحلول اللازمة لتلافيهاء. ومن أهم المتطلبات التي ينبغي توافرها عند البدء بنطبيق إدارة

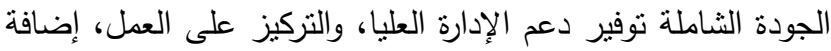
إلى وجود نظام للقياس، وممارسة النمط القيادي الدناسب، وأخيراً

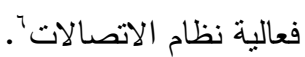
يُعتبر تطبيق إدارة الجودة الثاملة في المؤسسات عملية ليست سهلة وتحتاج إلى وقت طويل لاستكمال مراحلها، فإدارة الجودة الثاملة هي منهجية عملية منطورة ترتبط بكافة نشاطات الجامعة وتهدف إلى تحسين جودة المنتج من أجل إرضاء العميل وإسعادهّا. إن الحرص على إنجاح المشاريع مطلبٌ سياسيٌ واقتصاديّ،

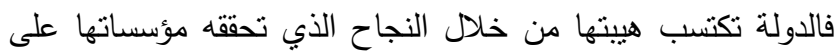

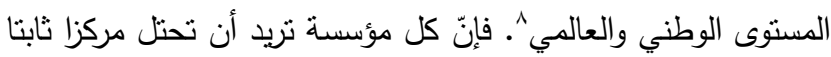

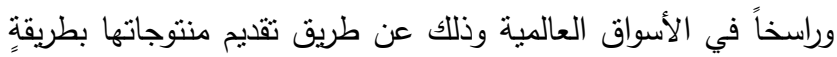

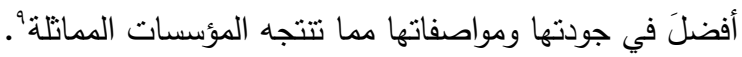

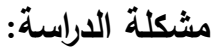

يحظى التعليم العالي باهتمام الحكومات والمؤسسات والأفراد،

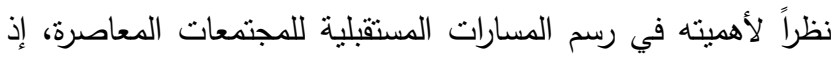

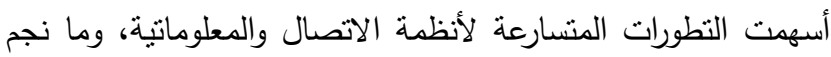

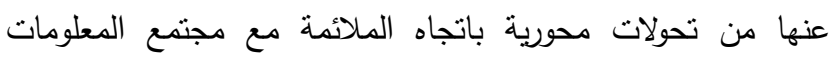

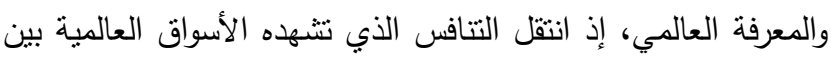
الثركات إلى مؤسسات التعليم العالي وإلى تتافس من نوع جديد محوره

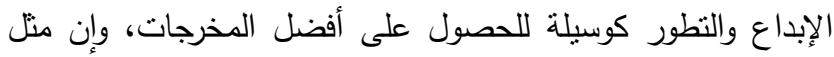

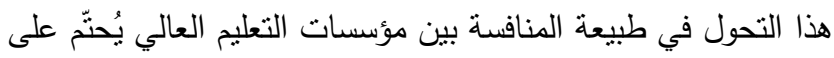
أي جامعة ترغب في التنافس عالمياً إعادة التفكير في استراتيجيتها وفلسفتها وكل ما من شانه التأثثر على قدراتها، لتتمكن من الدخول إلى المنافسة العالمية، وهي بذللك أمام مهام جديدة نركز على تقييم الذات لتحديد قدراتها التتافسية، وتقويم المنافسين لتحديد إمكاناتهم وقدراتهم وبموجب ما تقدم فهي تعمل على تحديد سلسلة من الأنشطة

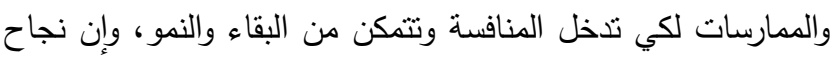
الجامعات في عملية التتافس مقترنٌ بالجودة النوعية في التعليم، والقدرة

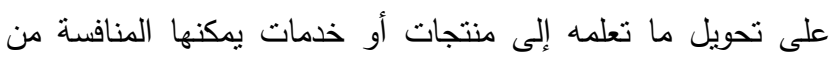

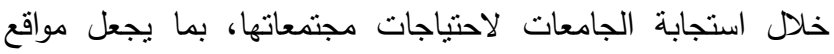


إدارة الجودة الثاملة في المؤسسات: الاقتصادية والصناعية والتكنولوجية والتجارية، وترجع فلسفة الجودة إلي العالم الأمريكي ديمنج والذي يُستّى بأبي الجودة، والذي اعتمد (Edward) Deeming) توزيعاً لتحسين الجودة من خلال تطبيقات الرقابة الإحصائية، ونظراً للنجاح الكبير الذي حققه هذا النهج الإداري بدأ الاهتمام باستخدامه في المؤسسات التربوية بدرجة متزايدة، ففي الولايات المتحدة تزايدت مؤسسات التعليم العالي التي تنتنى إدارة الجودة من (VA) مؤسسة عام

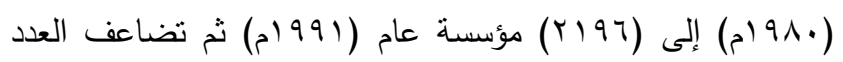

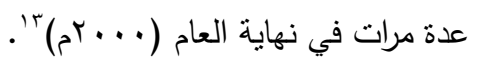
وزاد التتافس بين معظم المؤسسات في تطبيق هذا الأسلوب الإداري في كافة الدول المتقدمة وبعض الدول النامية التي بدأت تستخدم هذا الأسلوب في مؤسساتها المختلفة بما فيها التربوية، ومن الدول العربية التي بدأت استخدام هذا الأسلوب علي المستوي الإقليمي العربي السعودية والكويت وذلك في مدارسهما، فأصبحت برامجهما التربوية تخضع لمعايير الجودة الثاملة، حيث تعرف الجودة الثاملة في المؤسسات الاقتصادية "بأنها فلسفة إدارية حديثة نأخذ نهجاً أو نظاماً إدارياً شاملاً قائماً علي أساس إحداث تغييرات إيجابية جذرية لكل شيء داخل المؤسسة بحيث نشمل تلك التغييرات الفكر، السلوك، القيم، المعتقدات التتظيمية، المفاهيم الإدارية، نمط القيادة الإدارية،

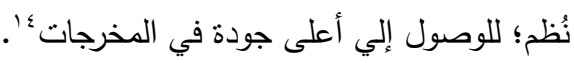
بينما تُعرّف إدارة الجودة الثاملة في المجال التعليمي بأنها "مجمل الصفات والخصائص التي تتعلق بالخدمة التعليمية والتي تفي باحتباجات الطلاب 1. وبمفهوم آخر هي "مدخل استراتيجي لإنتاج أفضل منتج أو خدمة من خلال الابتكار المنتج" ". إن إدارة الجودة الثاملة هي منهجية تتصف بالديمومة والاستمرار وليست محطة تنتهي بانتهاء برنامج معين أو زمن معين، لذا تتطلب المزيد من التدريب المستمر لحل المشكلات والتفكير بأساليب ابتكارية، وهي تطمح للوصول إلي رضا المستفيد الداخلي في المؤسسة التربوية ألا وهو الطالب والمعلم والإدارة التربوية، أما المستقيد الخارجي فهو رضا المجتمع عن نوعية المنتج التعليمي، وما سيحققه ذلك المنتج التعليمي من فائدة للمجتمع، لذا أصبح من أهم المعايير الدالة على نجاح المؤسسات التربوية هو نوعية الطالب الذي هي يتخرج من تلك المؤسسات التربوية وقدرته علي خدمة مجتمعه بالطريقة المطلوبة، كما أن نظرة المجتمع الإيجابية لتلك المؤسسة تكسبها نوعاً من الاحترام والتقدير ، الأمر الذي يؤدي إلى وجود منافسة شديدة بين المؤسسات التربوية المختلفة علي تحسين برامجها المختلفة وأهدافها للحصول علي مخرجات تعليمية مناسبة وملائمة لخدمة

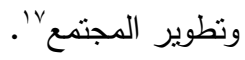

ولقد أكدت العديد من الدراسات العالمية التي تبنت إدارة الجودة الثاملة على أهمية ذلك النهج ونجاحه للحصول علي منتج صناعي
معرفة مدى نطبيق إدارة الجودة الثاملة في الجامعات الفلسطينية واللبنانية من وجهة نظر أعضاء هيئة التدريس. معرفة وجود فروقات في مدى تطبيق الجودة الثاملة في

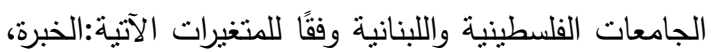
الكلية التي يعمل بها عضو هيئة التدريس، الرتبة العلمية.

حدود الدراسة:

الحدود الزمنية: طبقت الدراسة خلال الفصل الأول من العام

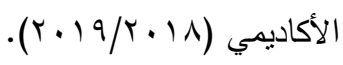

الحدود المكانية: الجامعات الفلسطينية واللبنانية.

الحدود البشرية: تقتصر هذه الدراسة على أعضاء هيئة التذريس في الجامعات الفلسطينية واللبنانية.

\section{مصطلحات الدراسة:}

الجودة في التعليم: الجودة في التعليم هي معابير عالمية للقياس والاعتراف، والانتقال من ثقافة الحد الأدنى إلى ثقافة الإتقان والتميز، واعتبار المستقبل هدفاً نسعى إليه، والانتقال من تكريس الماضي والنظرة الماضية إلى المستقبل الذي تعيش فيه الأجيال

وتعرف الجودة "إجرائياً" بأنها: الجهود العديدة المبذولة من قبل الإدارة العليا وجميع الأكاديمبين في الجامعات الفلسطينية واللبنانية لتحسين مُخرجات العملية التعليمية بما يتتاسب مع رغبات الطلبة وقدراتهم وخصائصهم واحتياجاتهم، وبما يلبي منطلبات المجتمع الفلسطبني واللبناني.

إدارة الجودة الشاملة: Total Quality Management (TQM) إدارياً شاملاً قائماً على أساس إحداث تغييرات إيجابية جذرية لكل شيء داخل الجامعة بحيث تشمل تللك التغيرات الفكر، السلوك، القيم، المعتقدات التظيمية، المفاهيم الإدارية، ونمط القيادة الإدارية؛ للوصول

$$
\text { إلى أعلى جودة في المخرجات ‘'. }
$$

مفهوم تطبيق الجودة الثاملة في الجامعات الفلسطينية واللبنانية إجرائياً: من خلال تطبيق الجودة الثاملة في الجامعات الفلسطينية واللبنانية، وبذل الجهود على جميع مسنويات الجامعة لرفع مسنوى أداء كافة الكليات والمراكز والإدارات والوحدات التابعة لها من خلال وضع خطة عمل تستهدف الارتقاء بمستوى خدمة التعليم العالي التي تقدمها للمجتمع من أجل تحقيق رضائه.

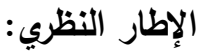

تعد إدارة الجودة الثاملة من المفاهيم الحديثة التي ظهرت نتيجة للمنافسة العالمية الثديدة بين مؤسسات الإنتاج: اليابانية والأمريكية والأوروبية، إذ تمكنت اليابان بفضل جودة منتجاتها من اكتساح الأسواق العالمية والفوز برضا المستهلكين حول العالم، جراء استخدام 
الجودة الثشاملة في اليابان بدرجة أكبر من الولايات المتحدة قال:

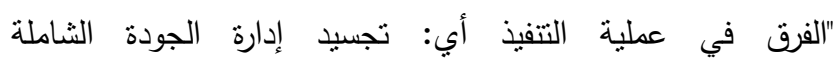

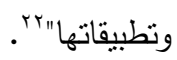

إن عملية تطبيق إدارة الجودة الثاملة تحتاج إلى توفير قياديين

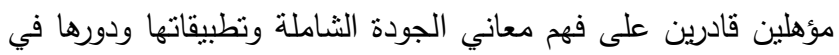
تحسين المنتج والمخرجات التعليمية بعيداً عن الخوف والتردد لاى نلك التكان القيادات، وهذا يتطلب تشجيع تلك القيادات علي إبداء آرائها بحرية نحو التغيير والتحسين والابتكار ويعني مفهوم إدارة الجودة الثشاملة بأنه " أسلوب متكامل يطبق في جميع فروع ومسنويات المنطقة التعليمية؛ ليوفر للأفراد وفرق العمل الفرصة لإرضاء الطلاب والمستفيدين من فن عملية التعلم، أو "هي فعالية تحقيق أفضل خدمات نعليمية بحثية

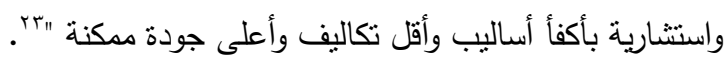
بينما رأى كرونسكي \أن إدارة الجودة الثاملة هي" فلسفة

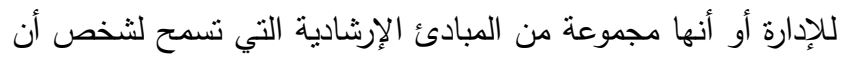

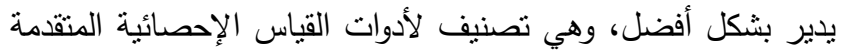

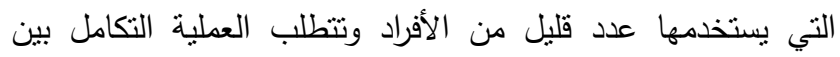

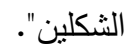
بينما رأى البعض الآخر أن إدارة الجودة الثاملة هي "أسلوب جديد للتفكير والنظر إلى المنظمة وكيفية التعامل والعمل داخلها

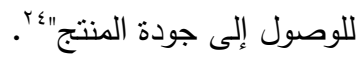
ورأى آخرون أن إدارة الجودة الثاملة هي "مدخل استراتيجي

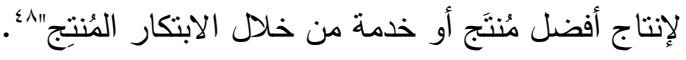

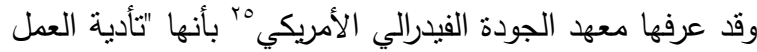
الصحيح على نحو صحيح من الوهلة الأولى مع الاعتماد على تقويم المستقيد في معرفة مدى تحسُّ الأداء". أما في القطاع التربويخ فإن إدارة الجودة الثاملة تعرف بأنها

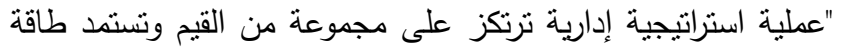
حركتها من المعلومات التي نتمكن في إطارها توظيف مواهب العاملين

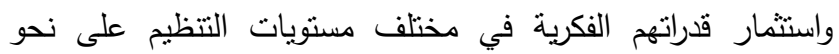
إبداعي لتحقيق التحسن المستمر للمنظمة". ويركز هذا التعريف على مفهوم إدارة النظم الذي يربط بين الدخلات والعمليات والئخرجات للعملية التعليمية، وبالتالي ينطلب هذا الدفهوم النظر إلى كل من الطلاب المستفيدين بصورة مباثرة من هذا الأسلوب وكيفية الإعداد لهم لتحقيق حاجاتهم ورغباتهم الحالية والمستقبلية الأمر الذي سينعكس على المجتمع بمؤسساته المختلفة، وكذلك المعلمين والإداريين والعاملين الذين هم بحاجة إلى تدريب وتطوير لمهاراتهم وكفاياتهم لاستيعاب فلسفة ومفاهيم الجودة الثاملة

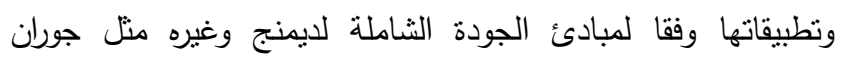

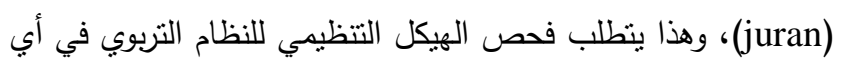

قادر على المنافسة في الأسواق العالمية، وكذلك الحصول على منتج

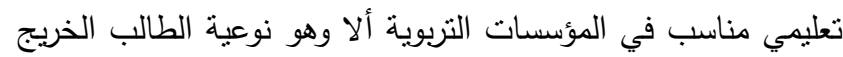
من تلاك المؤسسات التربوية القادر على الإسهام بتتمية المجتمع بكافة

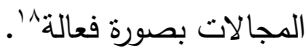

\section{الاتجاهات الحديثة في إدارة الجودة الثاملة:}

مفهوم الجودة (Quality): إن مصطلح الجودة هو بالأساس مصطلح اقتصادي ظهر بناءً علي التتافس الصناعي والتكنولوجي بين

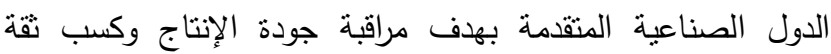

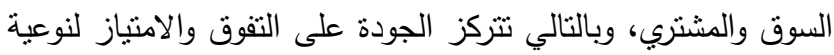
المنتج في أي مجال، وتعرف الجودة ضمن مفهوم إدارة الجودة الثشاملة بأنها "مقابلة وتجاوز توقعات المستفيد"ه؛ وبالتالي يقوم (TQM)

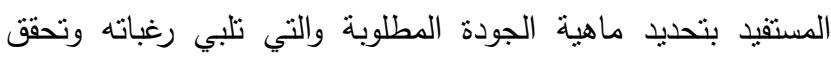
رضاه، وهنا يكمن التحدي والصعوبة في إرضاء جميع المستقيدين والذين تختلف أهواؤهم ورغباتهم ولهم شخصيات مختلفة وينتمن

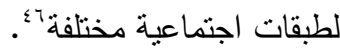
أما مفهوم الجودة في التعليم فإنه يتعلق بكافة السمات والخواص التي تتعلق بالمجال التعليمي والتي تظهر مدي التفوق والإنجاز للنتائج المراد تحقيقها، "وهي ترجمة احتباجات توقعات الطلاب إلى خصائص

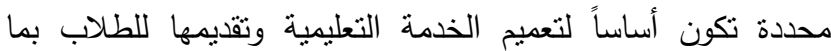

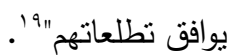
وبالتالي تسعى الجودة الثشاملة إلى إعداد الطلاب بِيماتٍ معينة تجعلهم قادرين على معايشة غزارة المعلومات وعمليات التغيير المستمرة، والتقام التكنولوجي الهائل، لا حصر دورهم فقط في نقلاً للمعرفة والإصغاء، لذلك فإن هذه المرحلة تتطلب "إنسانا ذا مواصفات

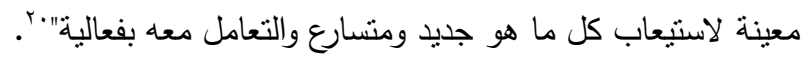

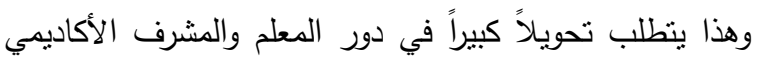

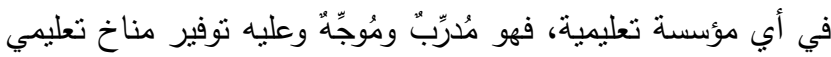

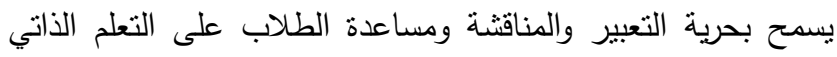

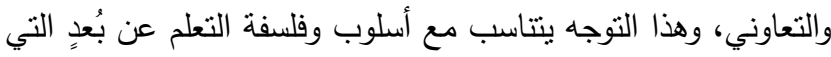
تتنهجها الجامعات المفتوحة والتي تعتمد على الطالب في عملية التعلم مع توفير كل الإمكانات اللازمة لحدوث التعلم بمساعدة المشرف لعند

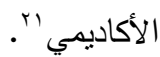
ولقد ظهر مفهوم إدارة الجودة الثاملة (TQM) بعد الأزمة التي

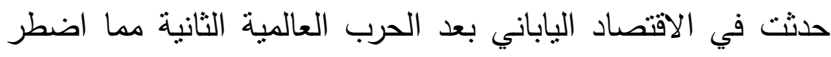

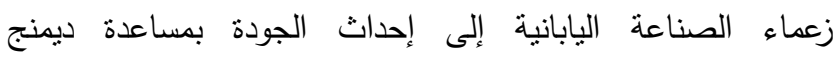
الأمريكي الذب يُسمّى بأبي الجودة، والذي قام بتعليم (Deeming) المنتجين اليابانيين كيفية تحويل السلع الرخيصة والرديئة إلى سلع ذات الاتئي

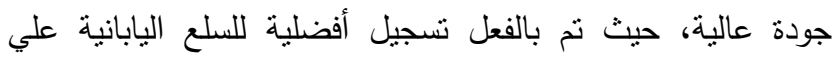
المنتجات الأمريكية، وعندما سئل (ديمنج) عن سبب نجلئ نجاح إدارة 
العوامل الثقافية المؤثرة في إدارة الجودة الثاملة في التعليم

(العالي:

تهتم إدارة الجودة الثناملة بفلسفة تعتمد على استراتيجية طويلة المدى في تحقيق أهدافها، ولا نقاس نتائجها من خلال فترة قصيرة، تلاكية

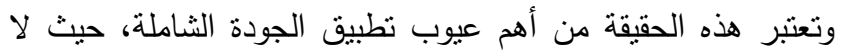

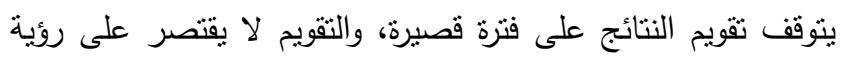
المؤسسة لنفسها أو من وجهة نظرها ولكن نوجد قوى وعوامل أخرى تحدد نوعية المخرجات التعليمية على اعنبار أن المخرجات التعليمية تعتبر سلعة تتافسية خاضعة للتقويم بشكل مستمر، وللحصول على الى الى

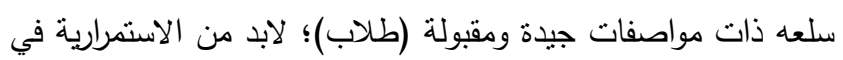

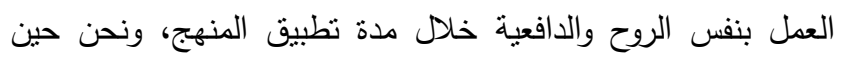

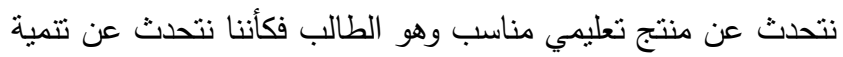

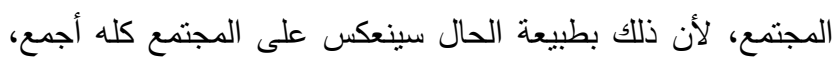

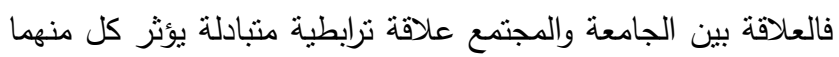

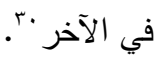

ويخضع تطبيق إدارة الجودة الثاملة في كافة المجالات بما فيها

المجال التعليمي الجامعي لمجموعة من القوى الثقافية المؤثرة في

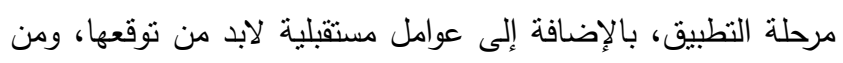

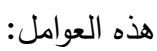

العامل الاقتصادي: حيث يرتبط النمو والتطوير التزبوي بالحالة

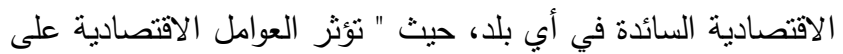

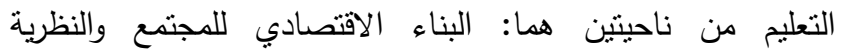

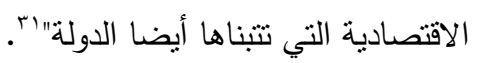

العامل السياسي: وهو يتعلق بنظام الحكم المنبع في الدولة الدانة والظروف السائدة المرتبطة بهذا النظام السياسي وما ينبعها من لنافي استقرار سياسي، حيث تظهر فلسفة الحكم في ظل النظم الديمقراطية التي تقوم على نقة واحترام الفرد، وأن السياسة هي نتاج لقرار الفرد

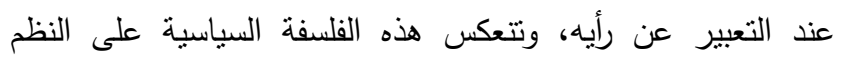

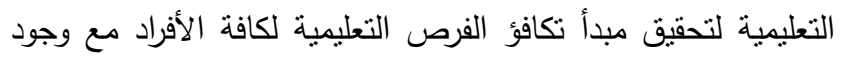
نوع محدد من الإثراف على التعليم لتحقيق الوحدة والاحتفاظ بالدولة كثريك مباشر في عملية التعليمَّ. العامل الحضاري: "إن التقدم الحضاري في أي مجنمع يقوم على ثلاث ركائز أساسية هي: القوى البشرية، المنظمات والمؤسسات الفيات

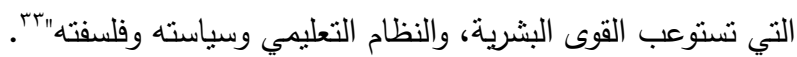
العامل الاجتماعي: بشكل النظام الاجتماعي في أي دولة عاملاً

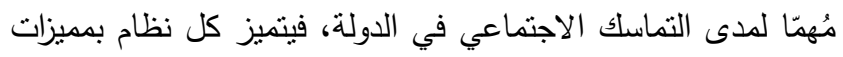
اجتماعية تميزه عن غيره، ويرتبط الوضع الاجتماعي بالوضع السياسي فئي

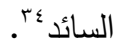

إن تطبيق إدارة الجودة الثاملة في العديد من المؤسسات

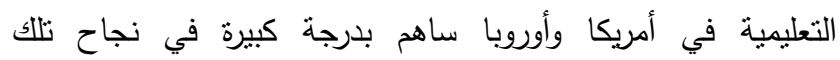

مؤسسة تعليمية؛ كي يتوافق مع فلسفة إدارة الجودة الثاملة مع توفر

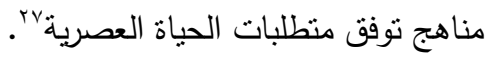
وانطلاقا من هذه التعريفات فإن إدارة الجودة الثناملة في إطار

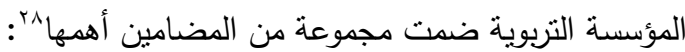

اعتماد أسلوب العمل الجماعي التعاوني، ومقدار ما يمتلكه العنصر البشري في المؤسسة من قدرات ومواهب وخبرات. الحرص على استمرار التحسين والتطوير لتحسين الجودة.

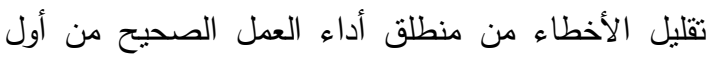

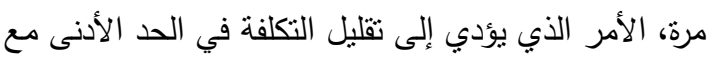

الحصول على رضا المستفيدين من العملية التعليمية. الحرص على حساب تكلفة الجودة داخل المؤسسة لتشمل كافة الأعمال المتعلقة بالخدمة الدقدمة متل تكاليف الفرص الضائعة، تكلفة الأخطاء، عمليات التقويم، سمعة المؤسسة. النهج الثنمولي لكافة المجالات في النظام التعليمي: كالأهداف والهيكل التنظيمي وأساليب العمل والدافئية

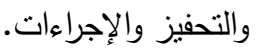

\section{عوائق تطبيق الجودة الشاملة في التعليم الجامعي العالي:}

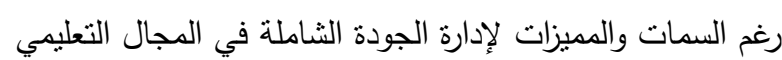

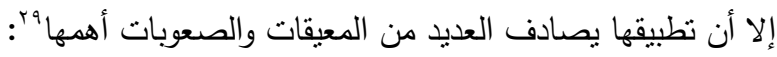
المركزية في اتخاذ القرار التربوي لأن إدارة الجودة الثاملة بحاجة إلى نظام لامركزي يسمح بالمزيد من الحريات والابتكار في العمل بعيداً عن الروتين والتعقيدات الإدارية بلإنية التي تضعف العمل والأداء.

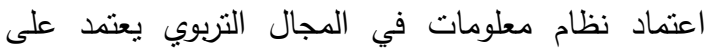

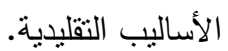

ضعف الكوادر المدربة والمؤهلة في مجال إدارة الجودة الثاملة في المجال التزبوي والقادرة علي تحمل المسئولية

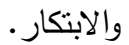
يحتاج تطبيق إدارة الجودة الثشاملة إلى ميزانية كافية غير عادية. عدم تقبل الإداريين والعاملين أساليب التطوير والتحسين، لأنها تتطلب منهم مهارات وكفايات لا يسنطيعون تحملها كما تُشبّب لهم ضعفاً مع سلطتهم الإدارية. الإرث الثقافي والاجتماعي الذي يرفض تقبل ما هو جديد

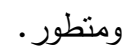
ضعف الأنماط القيادية لدى المديرين والإداريين أصحاب القرار في الميدان التربوي. ضعف العلاقة بين المؤسسات التعليمية والمجتمع المحلي، وضعف عمليات المشاركة في اتخاذ القرارات. 
لأعضاء هيئة التدريس، اختيار قيادات تمنلك خبرات تشرف على تطبيق برنامج الجودة الثاملة. دراسة بروش وبركان^^ تحت عنوان: مشروع تطبيق نظام ضمان الجودة في مؤسسات التعليم العالي في الجزائر : الواقع والآفاق. وقد هدفت الدراسة، إلى ابراز أهية ضمان الجودة بمؤسسات التعليم

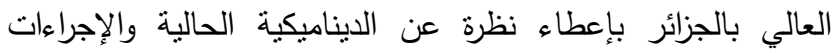
المتخذة من طرف وزارة التعليم العالي من أجل تطبيق ضمان الجودة

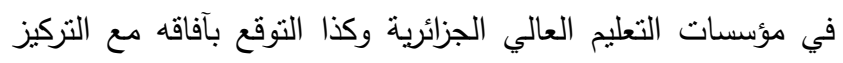
على المعوقات. وقد خلصت الدراسة إلى: غياب ثقافة الجودة في التعليم العالي، قلة مستوى تكوين وتدريب القائمين عليها، عدم توافر

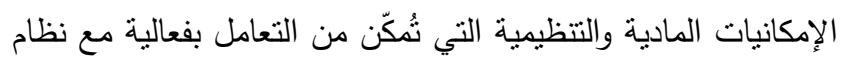

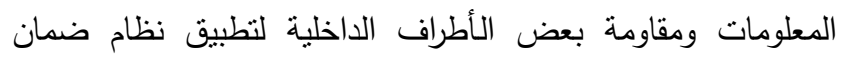

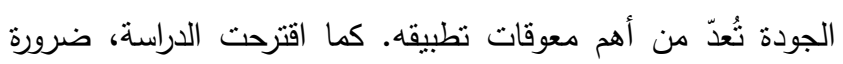
الاهتمام بالاتصال الفعال والمشاركة كعوامل أساسية للتخفيف من حدة

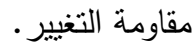

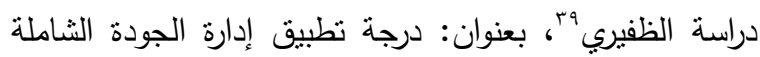

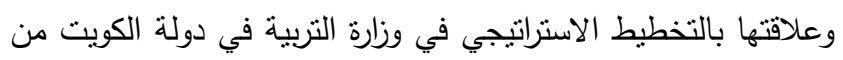
وجهة نظر الإداريين" هدفت إلى تعرف درجة تطبيق إدارة الجودة الثناملة وعلاقتها بالتخطيط الاستراتيجي في وزارة التربية في دولة التانية

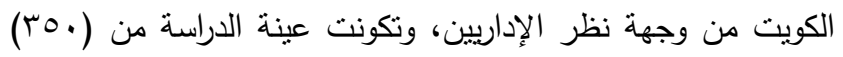
موظفاً في وزارة التربية بدولة الكويت، ولتحقيق أهداف الدراسة، تم الاعتماد على المنهج الوصفي التحليلي، حيث أثشارت أبرز النتائج إلى وجود درجة منوسطة لنطبيق إدارة الجودة الثاملة في وزارة التربية في دولة الكويت من وجهة نظر الإداريين، كما أنشارت إلى وجود فروق ذات دلالة إحصائية في درجة تطبيق إدارة الجودة الثاملة، في الإداين،

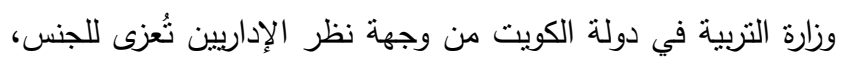
وللمؤهل العلمي لصالح حملة الماجستير ، ولسنوات الخبرة لصالح ذوي

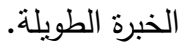

دراسة أبو عبده،؛ بعنوان: " درجة تطبيق معايير إدارة الجودة

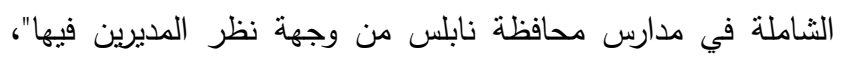

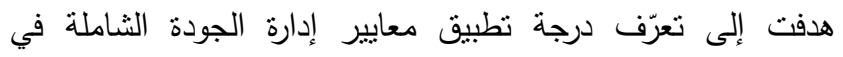
المدارس الفلسطينية في محافظة نابلس من وجهة المديرين فيها، بالإضافةٍة إلى تحديد دور متغيرات كل من الجنس والمؤهل العلمي فئي والتخصص وسنوات الخبرة والسلطة المشرفة على ذلك، وتكونت دئت عينة الاراسة من TY مديرا ومديرة من مديري ومديرات مدارس محافظة نابلس، ولتحقيق أهداف الدراسة تم الاعتماد على المنهج الوصفي التحليلي؛ باستخدام استبانة، حيث تم تحليل البيانات باستخدام برنامج التاني الرزم الإحصائية للعلوم الاجتماعية SPSS، وأظهرت أبرز النتائج

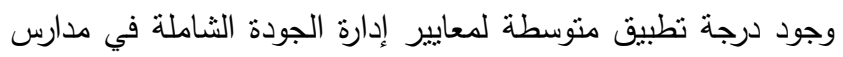
محافظة نابلس من وجهة نظر المديرين والمديرات فيها في جميع
المؤسسات في تحقيق أهدافها بدون إحداث هدر تربوي، كما لبى

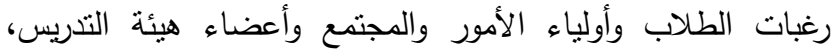
بالإضافة إلى تحسين طرق التدريس ووسائل التقويم وتصميم مناهج تربوية تلائم عمليات التعلم الذاتي، وهذا ينطلب توفير الجهد والصبر على تحقيق النتائج دون استعجال من قبل الإدارات العليا في الجامعات الفلسطينية واللبنانية باعتبار أن التعلم هو عملية مستمرة مدى الحياة، كما يتطلب أنماطاً قيادية ديمقراطية تؤمن بالتشاركية والتعاون بين جميع المشاركين؛ ليسود بينهم التقدير والاحترام ويتمتعوا

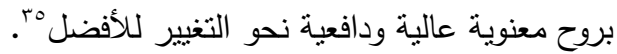

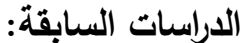

من خلال الاطلاع على الأداء التزبوي استطاع الباحثون توثيق بعض الدراسات التي لها علاقة بموضوع الدراسة وهي كالتالي:

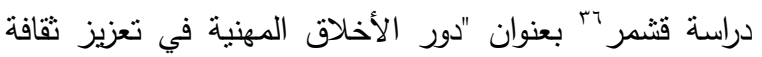

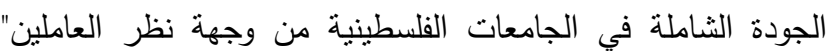
حيث هدفت الدراسة الى التعرف على دور الأخلاق المهنية في تعزيز

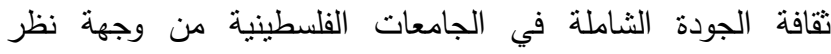

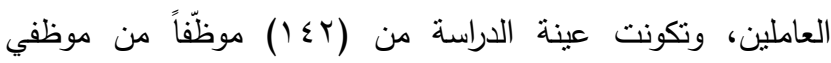

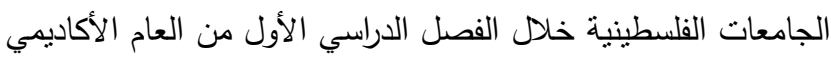

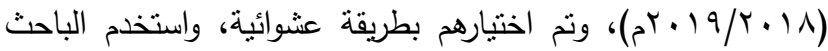

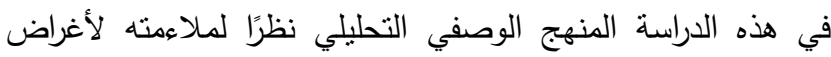

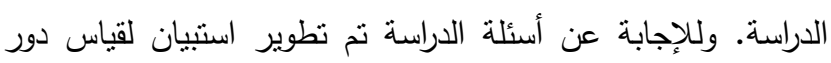
الأخلاق المهنية في تعزيز تقافة الجودة الثاملة في الجامعات الفلسطينية من وجهة نظر موظفيها، حيث تكوّن الاستيان من (ro) فقرة، وباستخدام مدرج ليكرت الخماسي. وتم التأكد من صدق الأداة من خلال عرضها على مجوعة من المختصين من أعضاء هيئة التدريس في الجامعات الفلسطينية، وأوصوا بصلاحيتها بعد إجراء تعديلات أثناروا إليها، وقد نم إجراء تلاك التعديلات وإخراج الاستبانة بصورتها النهائية. وبناءً على ما توصلت إليه الدراسة من نتائج

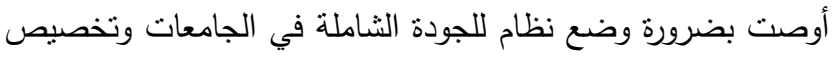
قسم مسؤول لهذا الموضوع واهتمام المسئولين بالجامعة لتحقيق الجودة الثشاملة، وإعادة هيكلة الجامعات وفقاً لمعايير إدارة الجودة الثاملة. دراسة العضاضي rv تحت عنوان: معوقات تطبيق إدارة الجودة الثاملة في مؤسسات التعليم العالي: دراسة ميدانية. وقد هدفت الدراسة إلى تحديد المعوقات التي تحول دون تطبيق إدارة الجودة في مؤسسات

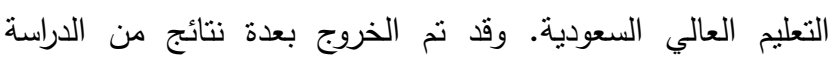
الميدانية كان أهمها: عدم قناعة بعض القيادات الأكاديمية بتطبيق إدارة الجودة الثاملة، غموض سياسات واستراتيجيات نطبيق إدارة الجودة الثاملة، ضعف الحوافز المالية والمعنوية. وقد تم اقتراح عدد من التوصيات، كان أهمها: نشر نقافة الجودة، الاهتمام بالحوافز 
فرق العمل، أما فيما يتعلق بتقدير واحترام العاملين للتطبيق فقد أظهرت نتائج الدراسة وجود نوجه منوسط أيضاً.

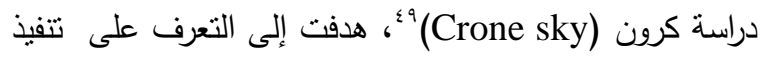

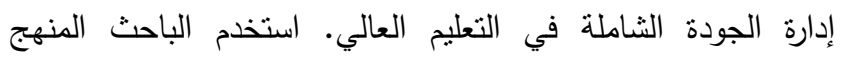
الوصفي حيث استعرضوا مشكلة التعليم العالي الأمريكي، ونسبوها إلى لى لئي

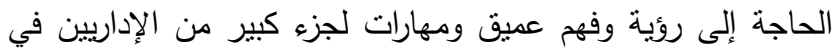
مؤسسات التعليم العالي، وذلك بسبب عدم توفر عدد كاف من التدريب سواء كان إداريا رسميا أو غير رسمي، وتطرق الباحث لبعض الأمتلة

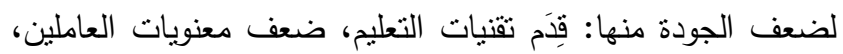
ضعف إعداد الهيئة التدريسية، الميزانية غير السلمية، الإعداد الضعيف للمهنيين، والمهارات غير الكافية للطلاب الجدد، وفي نهاية البحث اقتزح الباحث على الدراء منهجا مختصرا لنظريات متعددة في

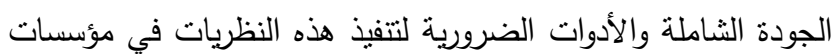
التعليم العالي.

دراسة هيرنانديز (Hernandes)؛。، هدفت الدراسة إلى

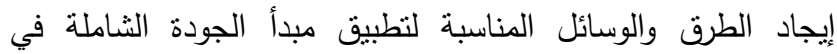
المنطقة التعليمية في إحدى الولايات الأمريكية وهي ولاية تكساس. وقد

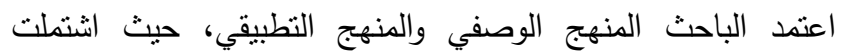
العمليات المستخدمة لنطبيق مدخل (T.Q.M) تدريب الإداريين الجدد والمعلمين الذين لا يزالون في الخدمة، وأكاديمية قيادة المنطقة

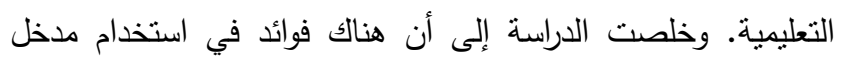
إدارة الجودة الثاملة تجاه المنطقة التعليمية وظهرت الفوائد من خلال انتشار نقافة الجودة فيها وتغير بسيط طرأ على العاملين ومدخل النظم في تلاك الولاية.

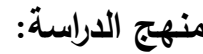

اتبعت الدراسة المنهج الوصفي التحليلي، ويقصد بالمنهج

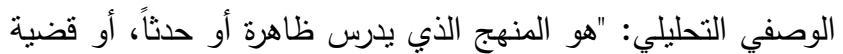
موجودة حالياً يمكن الحصول منها على معلومات تجيب عن أسئلة

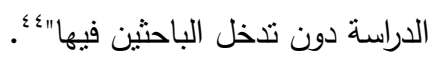

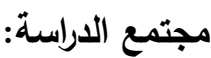

تكون مجتمع الدراسة من جميع أعضاء الهيئة التدريسية المتفرغين والناطقين باللغة العربية في الجامعات الفلسطينية واللبنانية من حملة شهادتي الدكتوراه والماجستير خلال الفصل الأول العام

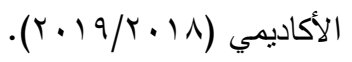

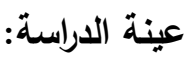

تم اختيار عينة عشوائية من أعضاء هيئة التنريس في

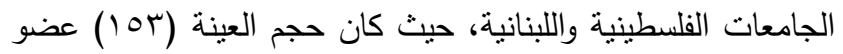
هيئة تدريس خلال الفصل الأول من العام الأكاديمي

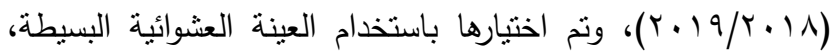

المجالات، كما أظهرت عدم وجود فروق دالة إحصائياً في درجة تطبيق معايير إدارة الجودة الثناملة في مدارس محافظة نابلس، تُعزى دادي لمتغيري الجنس والمؤهل العلمي، بالإضافة إلى وجود فروق دالة إحصائياً تُعزى لمتغير سنوات الخبرة، ولمتغير التخصص. دراسة الدقي '، التي هدفت إلى الكثف عن واقع تطبيق معايير وركائز إدارة الجودة الثاملة في وزارات السلطة الوطنية الفلسطينية في قطاع غزة، والمعوقات التي تحول دون تطبيقها. لذا قام الباحث

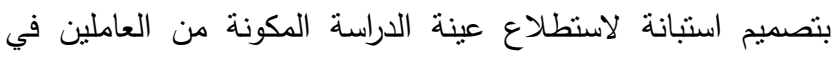
الوزارات الفلسطينية في قطاع غزة والتي بلغ عددها (·rع) موظفاً، واستخدم الباحثون مجموعة من الأساليب الإحصائية لتحليل بيانات

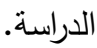

وقد نوصلت الدراسة إلى نتائج كان أهمها وجود اقتتاع ورغبة

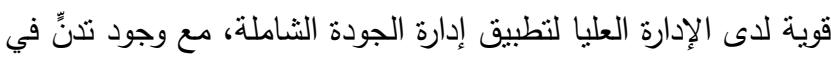
درجة الالتزام والدعم لعمليات التحسين والتطوير ، وسوء استغلال وتقييم فرص التنريب المتاحة، ووجود نقص في مسنوى وعي العاملين حول عملية تطبيق إدارة الجودة الثاملة. دراسة علوان؟؟، هدفت الدراسة إلى تقييم فرص تطبيق مدخل إدارة الجودة الثشاملة، بغرض قياس درجة نوافر الأبعاد والعناصر

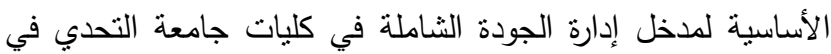
الجماهير الليبية. اعتمد الباحث في دراسته على المنهج الوصفي

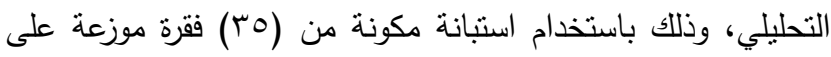
خمسة مجالات من مفاهيم إدارة الجودة الثاملة، وقد انشتلت عينة الدراسة على (^^) إدارياً أكاديمياً و(•^) عضو هيئة تدريس، حيث تم اختيار أفراد عينة الدراسة بالطريقة العشوائية للعام الدراسي الديا

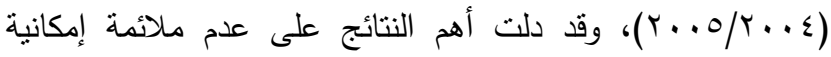
تطبيق مبادئ إدارة الجودة الثاملة في كليات جامعة التحدي من وجهة الته نظر عينة الدراسة نظراً لأن ثقافة الكليات وبنيتها النتظيمية لا نساعد على ذللك. دراسة الناطور ״ّ، هدفت هذه الدراسة إلى الوقوف على مستوى

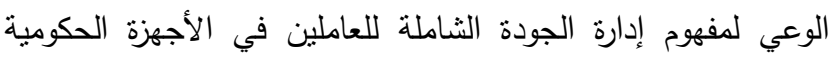

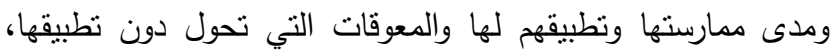
وهل هناك فروق ذات دلالة إحصائية للعاملين في الأجهزة الحكومية تُعزى للمتغيرات الثخصية المتنلة بالجنس والمؤهل العلمي والمستوى لهن الوظيفي وسنوات الخبرة، وتم اختيار عينة الدراسة الككونة من العاملين

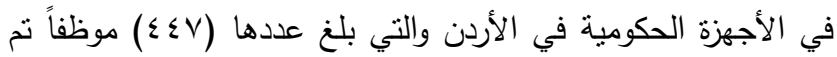
اختيارهم من بين (YAN) موظفاً. وتوصلت الدراسة إلى أن وعي الآدي العاملين لدفهوم تطبيق إدارة الجودة الثاملة بدرجة كبيرة مع وجود فروق ذات دلالة إحصائية للمؤهلات العلمية في حين كان التوجه لديهم بدرجة منوسطة لنطبيق هذا المفهوم، وبدرجة مشابهة لتكوين 


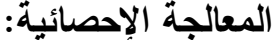

بعد جمع البيانات تم إدخالها للحاسب لتعالج بواسطة البرنامج الإحصائي للعلوم الاجتماعية (SPSS)، وقد استخذت النسب المئوية والمتوسطات الحسابية الموزونة واختبار (ت) وتحليل التباين الأحادي.

\section{نتائج الاراسة ومناقشتها:}

أولاً: النتائج المتعلقة بالسؤال الأول الذي نصده: ما مدى نطبيق

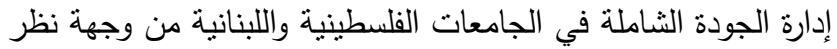

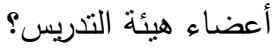
من أجل الإجابة عن هذا السؤال، استخدمت المتوسطات الحسابية والنسب المئوية لكل فقرة من فقرات كل مجال من مجالات

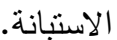

وقد أعطي للفقرات ذات المضمون الإيجابي (0) درجات عن

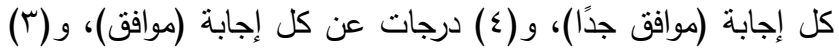

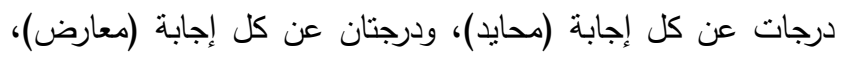
ودرجة واحدة عن كل إجابة (معارض جدًا)، وقد نم عكس الدرجات على الفقرات السلبية. ومن أجل تفسير النتائج اعتُد الميزانُ الآتي للنسب المئوية

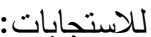

\begin{tabular}{|c|c|}
\hline درجة الاستجابات & النسبة المئوية \\
\hline منخفضة جدًا & أقل من .0\% \\
\hline منخفضة & من .0\%-\% \% \% \\
\hline متوسطة & من . . \% \% \% \% \\
\hline مرتفعة & \%vq- \%v. من \\
\hline مرنفعة جدًا & من .^^\% فما فوق \\
\hline
\end{tabular}

$$
\text { ويبين الجدول (†)، النتائج. }
$$

النتائج المتعلقة بالبعد الأول (التزام الإدارة العليا بالجودة الثاملة) جدول رقم (૫): المتوسطات الحسابية والنسب المئوية للبعد الأول.

\begin{tabular}{|c|c|c|c|c|}
\hline الاستجابة & المئوية - النسبة & | الاستجابة" & الفقرات & $\#$ \\
\hline مرتفعة جدا & $\% 84$ & 4.20 & 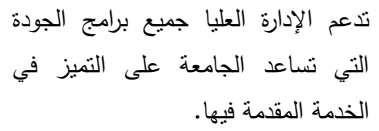 & 1 \\
\hline مرتفعة جدا & $\% 82$ & 4.08 & التقوم الإدارة العليا بخلق البيئة المناسبة & $r$ \\
\hline مرتفعة جدا & $\% 80$ & 4.00 & 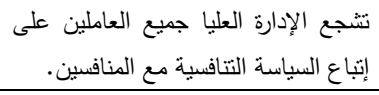 & $r$ \\
\hline مرتفعة جدا & $\% 81$ & 4.06 & 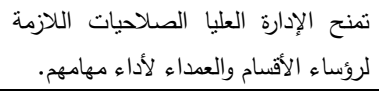 & $\varepsilon$ \\
\hline مرتفعة جدا & $\% 82$ & 4.10 & 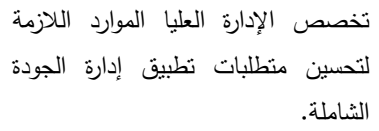 & 。 \\
\hline مرتفعة جدا & $\% 82$ & 4.09 & الدرجة الكلية & \\
\hline
\end{tabular}

بحيث كان لكل فرد من مجتمع الدراسة الفرصة ليكون ضمن عينة

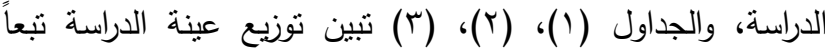

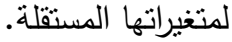

جدول رقم (1): توزيع عينة الدراسة تبعاً لمتغير الرتبة العلمية.

\begin{tabular}{|c|c|c|}
\hline النسبة المئوية & التكرار & الرتبة العلمية \\
\hline$\% 32$ & 49 & محاضر \\
\hline$\% 23$ & 35 & أستاذ مساعد \\
\hline$\% 24$ & 36 & أستاذ مشارك \\
\hline$\% 22$ & 33 & أستاذ دكتور \\
\hline$\% 100$ & 153 & المجموع \\
\hline
\end{tabular}

جدول رقم (ץ): توزيع عينة الاراسة تبعا لمتغير الكلية التي يعمل بها عضو هيئة التدريس.

\begin{tabular}{|c|c|c|}
\hline النسبة المئوية & 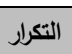 & الكلية التي يعمل بها عضو هيئة التدريس \\
\hline$\% 30$ & 46 & الكليات العلمية \\
\hline$\% 46$ & 71 & 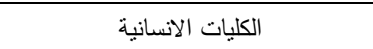 \\
\hline$\% 24$ & 36 & كلية الدراسات العليا \\
\hline$\% 100$ & 153 & المجموع \\
\hline
\end{tabular}

جدول رقم (r): توزيع عينة الدراسة تبعا لمتغير سنوات الخبرة.

\begin{tabular}{|c|c|c|}
\hline النسبة المئوية & التكرار & سنوات الخبرة \\
\hline$\% 39$ & 60 & أقل من (0.) سنوات \\
\hline$\% 29$ & 44 & من (0.-..r) سنة \\
\hline$\% 32$ & 49 & أكثر من (·r) سنة \\
\hline$\% 100$ & 153 & المجموع \\
\hline
\end{tabular}

أداة الدراسة:

اعتماداً على أدبيات البحث والدراسات السابقة واستثارة الخبراء تم بناء استبانة لجمع البيانات من عينة الدراسة اشتملت على (ع () فقرة موزعة على (r) مجالات. جدول رقم (؛): فقرات الاستبانة تبعا لمجالات الدراسة.

\begin{tabular}{|c|c|c|c|}
\hline الفقرات & عدد الفقرات & الأبعاد & \# \\
\hline $.0-.1$ & 0 & التزام الإدارة العليا بالجودة & 1 \\
\hline $.9-.7$ & $\varepsilon$ & كفاءة القوى العاملة في الجامعة & r \\
\hline $1 \leq-1$. & 0 & إدارة عملية الجودة في الجامعة & $r$ \\
\hline
\end{tabular}

\section{صدق الأداة:}

تم عرض أداة الدراسة على عينة من المختصين في مجال جودة التعليم العالي في كلٍ من الجامعات الفلسطينية واللبنانية، وأوصوا بصلاحيتها بعد إجراء التعديلات المتعلقة بصياغة فقرات الاستيان، وقد تم إجراء تللك التعديلات وإخراج الاسنبانة بصورتها

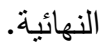

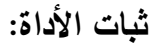

للتحقق من ثبات الأداة استخدمت معادلة كرونباخ ألفا لاستخراج الثبات فبلغت نسبته الكلية على فقرات الاستبانة (rی,· •) وهي نسبة ثبات تؤكد إمكانية استخدام الأداة. 


\begin{tabular}{|c|c|c|c|c|}
\hline الاستجابة & 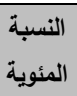 & الاستجابة * متوسط & الفقرات & $\#$ \\
\hline منوسطة & $\% 69$ & 3.47 & 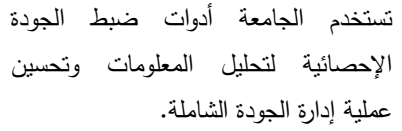 & $\varepsilon$ \\
\hline مرتفعة & $\% 76$ & 3.80 & 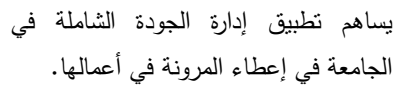 & 。 \\
\hline مرتفعة & $\% 73$ & 3.65 & الدرجة الكلية للمجال & \\
\hline
\end{tabular}

يتبين من الجدول رقم (^) السابق أن تطبيق إدارة الجودة

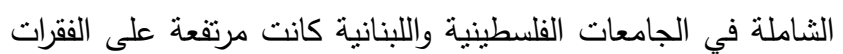
(1،1،، r، 0) حيث كان مستوى الاستجابة بين (70\%-79\%)، وكانت منوسطة على الفقرة (£) حيث كان مستوى الاستجابة عليها بين (69\%) وكانت النسبة المئوية للاستجابة على الدرجة الكلية

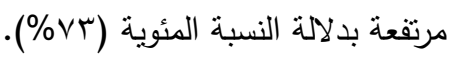
ويرى الباحثون أن سبب الارتفاع في النتيجة يعود الى الوعي الني ) بمفهوم إدارة الجودة لنطوير عمل مؤسساتها. خلاصة النتائج وترتيب الأبعاد والدرجة الكلية للاستجابات:

جدول رقم (9): المتوسطات الحسابية والنسب المئوية للابعاد والدرجة الكلية لكلاستجابات.

\begin{tabular}{|c|c|c|c|c|}
\hline الاستجابة & النئوية & الاستجابة " متوسط & 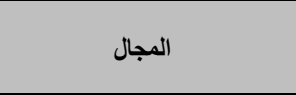 & $\#$ \\
\hline مرتفعة جدا & $\% 82$ & 4.09 & التزام الإدارة العليا بالجودة & 1 \\
\hline مرتفعة & $\% 78$ & 3.91 & كفاءة القوى العاملة في الجامعة & r \\
\hline مرتفعة & $\% 73$ & 3.65 & إدارة عملية الجودة في الجامعة & $r$ \\
\hline مرتفعة & $\% 78$ & 3.88 & الدرجة الكلية للججال & \\
\hline
\end{tabular}

يتبين من الجدول رقم (9) السابق أن نطبيق إدارة الجودة الثشاملة في الجامعات الفلسطينية واللبنانية كانت مرتفعة جدا على لئى

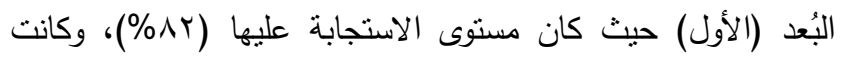
مرتفعة على الأبعاد (r، r) حيث كان مستوى الاستجابة عليها بين (70-79\%)، وكانت النسبة المئوية للاستجابة على الدرجة الكلية

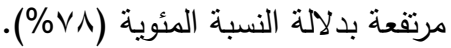

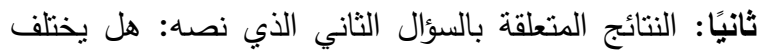
مدى تطبيق إدارة الجودة الثاملة في الجامعات الفلسطينية واللبنانية وفقًا للمتغيرات الآتية: الرتبة العلمية، الكلية التي يعمل بها عضو هيئة

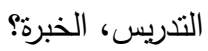

وتتعلق بهذا السؤال فرضيات الدراسة، والجداول (• ()، (1')، ( r ( ) تبين نتائج فحصها. نتائج فحص الفرضية الأولى التي نصها: لا توجد فروق ذات أتهات

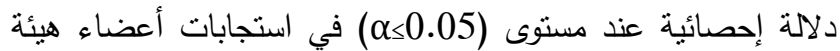
التدريس في الجامعات الفلسطينية واللبنانية تُعزى إلى اختلاف الرتبة العلمية.
يتبين من الجدول رقم (†) السابق أن تطبيق إدارة الجودة الثشاملة في الجامعات الفلسطينية واللبنانية كانت مرتفعة جدًا على الثى لإنى

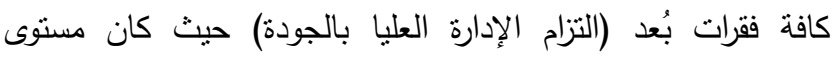
الاستجابة أكثر من (80\%)، وكانت النسبة المئوية للاستجابة على الإنى

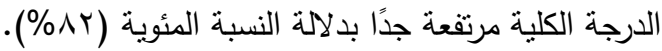
ويعود ذلك في نظر الباحثين إلى دعم الإدارة العليا والتزامها بتطبيق إدارة الجودة الثاملة في الجامعات الفلسطينية واللبنانية، كون

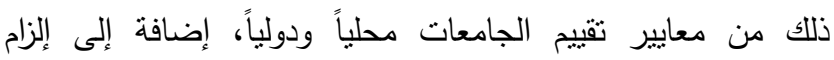
الجامعات بتطبيق الجودة الثاملة في كافة برامجها وإداراتها.

\section{النتائج المتعلقة بالبُعد الثاني (كفاءة القوى العاملة في الجامعة)}

جدول رقم (V): المتوسطات الحسابية والنسب المئوية للبعد الثاني.

\begin{tabular}{|c|c|c|c|c|}
\hline الاستجابة & المئوية - المبة & متوسط الاستجابة * & الفقرات & \# \\
\hline مرتفعة & $\% 79$ & 3.96 & تطبيق مفهوم الجودة الثياملة. & 1 \\
\hline مرتفعة & $\% 82$ & 4.12 & تقلى ملى الجامعة على تدريب العاملين & $r$ \\
\hline مرتفعة & $\% 84$ & 4.20 & تنجاز الجامعة أسلوب فريق العمل في & r \\
\hline متوسطة & $\% 67$ & 3.35 & تلعنح الجامعة الحوافز المادية والمعنوية & $\varepsilon$ \\
\hline مرتفعة & $\% 78$ & 3.91 & الدرجة الكلية للمجال & \\
\hline
\end{tabular}

يتبين من الجدول رقم (V) السابق أن تطبيق إدارة الجودة

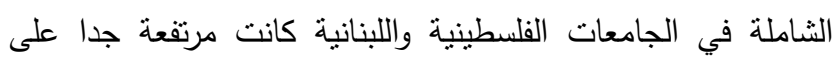

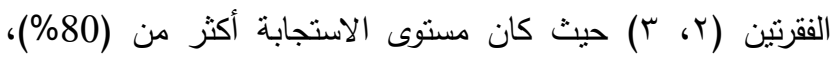
وكانت مرتفعة على الفقرة (1) حيث كان مستوى الاستجابة عليها

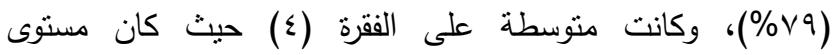
الاستجابة عليها بين (67\%) وكانت النسبة المئوية للاستجابة على

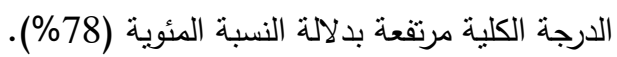
ويعود ذلك في نظر الباحثين إلى تفعيل عنصر المشاركة وتتكيل فرق العمل لاى الموظفين.

النتائج المتعلقة بالبعد الثالث (إدارة عملية الجودة الثاملة في

(الجامعة)

جدول رقم (^): المتوسطات الحسابية والنسب المئوية للبعد الثالث.

\begin{tabular}{|c|c|c|c|c|}
\hline الاستجابة & 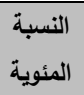 & متوسط & الفقرات & \# \\
\hline مرتفعة & $\% 74$ & 3.69 & تطويق الجامعة بتصميم عمليات و إجراءات & 1 \\
\hline مرتفعة & $\% 74$ & 3.69 & 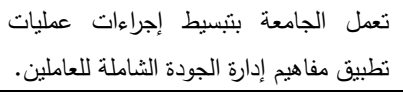 & $r$ \\
\hline مرتفعة & $\% 72$ & 3.59 & الجودة الثشاملة وطرق نحسينها والجامعة لإدارة مفاهيم & $r$ \\
\hline
\end{tabular}


الثاملة في الجامعات الفلسطينية واللبنانية تُعزى لمتغير الكلية التي يعمل بها عضو هيئة التدريس على كافة الأبعاد وعلى الدرجة الكلية

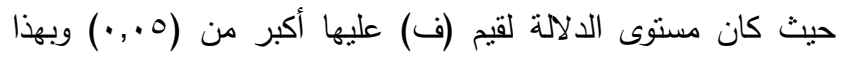
تقبل الفرضية الصفرية. نتائج فحص الفرضية الثالثة التي نصيّها: لا نوجد فروق ذات

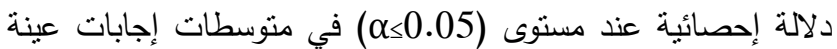
أفراد الدراسة بالنسبة لأثر تطبيق إدارة الجودة الثاملة في الجامعات الفلسطينية واللبنانية تُعزى إلى متغير الخبرة.

لفحص الفرضية استخدم تحليل التباين الأحادي (ANOVA) والجدول (r) (T) يبين النتائج: الجدول (r r) ( ) نتائج تحليل التباين الأحادي لالالة الفروق في تطبيق إدارة الجودة الثاملة في الجامعات الفلسطينية واللبنانية تعزى لمتغير سنوات الخبرة.

\begin{tabular}{|c|c|c|c|c|c|c|}
\hline "الدلالة " مستوى & قيمة & متوسط & الدرجية & مجريعات & مصدر التباين & المجال \\
\hline \multirow{3}{*}{.951} & \multirow{3}{*}{.050} & .029 & 2 & .058 & بين المجموعات & \multirow{3}{*}{$\begin{array}{c}\text { التزام الإدارة العليا } \\
\text { بالجودة }\end{array}$} \\
\hline & & \multirow[t]{2}{*}{.574} & 48 & 27.563 & داخل المجموعات & \\
\hline & & & 50 & 27.620 & المجموع & \\
\hline \multirow{3}{*}{.537} & \multirow{3}{*}{.630} & .270 & 2 & .541 & بين المجموعات & كفاءة القوى \\
\hline & & \multirow{2}{*}{.429} & 48 & 20.600 & داخل المجموعات & العاملة في \\
\hline & & & 50 & 21.140 & المجموع & الجامعة \\
\hline \multirow{3}{*}{.422} & \multirow{3}{*}{.878} & .495 & 2 & .990 & بين المجموعات & \multirow{3}{*}{ في الجارة علية الجودة } \\
\hline & & \multirow[t]{2}{*}{.564} & 48 & 27.057 & داخل المجموعات & \\
\hline & & & 50 & 28.047 & المجموع & \\
\hline \multirow{3}{*}{.880} & \multirow{3}{*}{.128} & .048 & 2 & .097 & بين المجموعات & \multirow{3}{*}{ الدرجة الكلية } \\
\hline & & .377 & 48 & 18.086 & داخل المجموعات & \\
\hline & & & 50 & 18.182 & المجموع & \\
\hline
\end{tabular}

ANOVA

يتبين من الجدول رقم (r I I) السابق عدم وجود فروق ذات دلالة

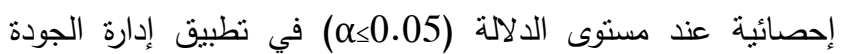
الثناملة في الجامعات الفلسطينية واللبنانية تُعزى لمتغير سنوات الخبرة على كافة الأبعاد وعلى والدرجة الكلية حيث كان مستوى الدلالة لقيم (ف) عليها أكبر من (0. (. •) وبهذا تقبل الفرضية الصفرية.

\section{المقترحات التوصيات:}

إجراء دراسات أخرى نتعلق بالجودة الثاملة في مؤسسات

$$
\text { التعليم العالي في مجتمعات أخرى. }
$$

الاهتمام بنوفير سبل اجتذاب الطلبة كأساس لنجاح تطبيق

$$
\text { إدارة الجودة الثاملة. }
$$

تتمية العمل الجماعي كفريق واحد ضمن الكوادر العامة في

$$
\text { الجامعات سواء الأكاديمية أو الإدارية. }
$$

اعتماد نظام الحوافز للموظفين وربط الحوافز بجودة العمل. تشكيل لجنة عليا للجودة في الجامعات الفلسطينية واللبنانية تتولى مهمة إقرار ورسم السياسات والخطط الاستراتيجية

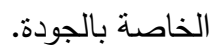

لفحص الفرضية استخدم تحليل التباين الأحادي (ANOVA)

$$
\text { والجدول (· (1) يبين النتائج: }
$$

\begin{tabular}{|c|c|c|c|c|c|c|}
\hline "الدلالة" & قيمة & متوبط & لدرجات & مجموع مريعات & مصدر التباين & المجال \\
\hline \multirow{3}{*}{.177} & \multirow{3}{*}{1.713} & .908 & 3 & 2.723 & بين المجموعات & \multirow{3}{*}{ العلزام الإدارة } \\
\hline & & \multirow[t]{2}{*}{.530} & 47 & 24.898 & داخل المجموعات & \\
\hline & & & 50 & 27.620 & المجموع & \\
\hline \multirow{3}{*}{.490} & \multirow{3}{*}{.819} & .350 & 3 & 1.050 & بين المجموعات & كفاءة القوى \\
\hline & & \multirow[t]{2}{*}{.427} & 47 & 20.090 & داخل الدجموعات & العاملة في \\
\hline & & & 50 & 21.140 & المجموع & الجامعة \\
\hline \multirow{3}{*}{.521} & \multirow{3}{*}{.762} & .434 & 3 & 1.301 & بين المجموعات & إدارة عملية \\
\hline & & \multirow[t]{2}{*}{.569} & 47 & 26.746 & داخل المجموعات & الجودة في \\
\hline & & & 50 & 28.047 & المجموع & الجامعة \\
\hline \multirow{3}{*}{.256} & \multirow{3}{*}{1.395} & .496 & 3 & 1.487 & بين المجموعات & \multirow{3}{*}{ الدرجة الكلية } \\
\hline & & \multirow[t]{2}{*}{.355} & 47 & 16.695 & داخل المجموعات & \\
\hline & & & 50 & 18.182 & المجموع & \\
\hline
\end{tabular}

الجدول (· (): نتائج تحليل التباين الأحادي للالالة الفروق في تطبيق إدارة الجودة

الثاملة في الجامعات الفلسطينية واللبنانية تُغزى لمتغير الرتبة العلمية.

يتبين من الجدول رقم (• (1) السابق عدم وجود فروق ذات دلالة إحصائية عند مستوى الدلالة (1)0.05) في نطبيق إدارة الجودة الثشاملة في الجامعات الفلسطينية واللبنانية تُعزى لمتغير الرتبة العلمية على كافة الأبعاد وعلى الدرجة الكلية حيث كان مستوى الدلالة لقيم (ف) عليها أكبر من (0. . •) وبهذا تقبل الفرضية الصفرية.

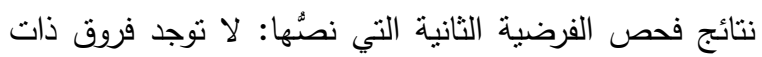
دلالة إحصائية عند مستوى (10.05) في استجابات أعضاء هيئة التدريس في الجامعات الفلسطينية واللبنانية تُعزى إلى اختلاف الكلية التي بعمل بها عضو هيئة التدريس. لفحص الفرضية استخدم تحليل التباين الأحادي (ANOVA)

$$
\text { والجدول (1) بيين النتائج: }
$$

\begin{tabular}{|c|c|c|c|c|c|c|}
\hline "الالالة" " مستوى & قيمة & متوسط & لدرجات & مجموع مربعات & مصدر التباين & المجال \\
\hline \multirow{3}{*}{.094} & \multirow{3}{*}{2.489} & 1.298 & 2 & 2.596 & بين المجموعات & التزام الإدارة \\
\hline & & \multirow[t]{2}{*}{.521} & 48 & 25.024 & داخل المجموعات & العليا \\
\hline & & & 50 & 27.620 & المجموع & بالجودة \\
\hline \multirow{3}{*}{.181} & \multirow{3}{*}{1.771} & .726 & 2 & 1.453 & بين المجموعات & كفاءة القوى \\
\hline & & \multirow[t]{2}{*}{.410} & 48 & 19.688 & داخل المجموعات & العاملة في \\
\hline & & & 50 & 21.140 & المجموع & الجامعة \\
\hline \multirow{3}{*}{.747} & \multirow{3}{*}{.294} & .170 & 2 & .339 & بين المجموعات & إدارة عملية \\
\hline & & \multirow[t]{2}{*}{.577} & 48 & 27.708 & داخل المجموعات & الجودة في \\
\hline & & & 50 & 28.047 & المجموع & الجامعة \\
\hline \multirow{3}{*}{.211} & \multirow{3}{*}{1.610} & .571 & 2 & 1.143 & بين المجموعات & \multirow{3}{*}{ الكلية } \\
\hline & & \multirow[t]{2}{*}{.355} & 48 & 17.039 & داخل المجموعات & \\
\hline & & & 50 & 18.182 & المجموع & \\
\hline
\end{tabular}

الجدول (11): نتائج تحليل التباين الأحادي لدلالة الفروق في تطبيق إدارة الجودة

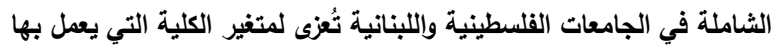
عضو هيئة التدريس.

يتبين من الجدول رقم (1) السابق عدم وجود فروق ذات دلالة إحصائية عند مستوى الدلالة (0.05 م) في تطبيق إدارة الجودة 
- Al-Naseer, Dalal Bint Manzil (2009). Experiences of Some International, Arab and Local Universities in the Application of Total Quality in Pursuit of Discrimination (published research), International Conference on Administrative Development towards outstanding performance in the government sector, Riyadh, Saudi Arabia

- Al-Nashash, Hayam Muhammad (2006). Developing a Quality Assurance Model in Jordanian Universities in the Light of Reality and International Models. Unpublished $\mathrm{PhD}$ thesis, Amman Arab University: Amman, Jordan.

- Al-Otaibi, Nawaf Mohammed (2006). A Proposed Model for Total Quality Management at Kuwait University in the Light of the Perceptions of Leaders and Faculty Members for their Applicability. Unpublished $\mathrm{PhD}$ thesis, Amman Arab University: Amman, Jordan.

- Alwan, Qasim Nayef (2005). Total Quality Management and Its Applicability in The Challenge, the Fifth Educational Conference: The Quality of University Education, from (11-13) April - University of Bahrain: College of Education.

- Ayesh, Shadi Atta Mohammed (2008). The Iimpact of the Application of Total Quality Management on Institutional Performance. Unpublished Master of Business Administration, Islamic University of Gaza, Palestine.

- Bridge, Samir (2004). Reorganization of Private Higher Education, a working paper presented to a workshop at the Ministry of Education and Higher Education, Directorate General of Higher Education, Beirut, Lebanon, 10-24 February.

- Broch, Zinedine \& Berkane, Youssef (2012). Implementation of the Quality Assurance System in Higher Education Institutions in Algeria. Reality and Prospects ", at the 2nd Arab International Conference on Quality Assurance in Higher Education, Gulf University, Kingdom of Bahrain, on (4/5) April.

- Cronesky, Robert, ET. Al., (2003). Implementing Total Quality Management in Higher Education, St. Edward's university, USA.

- Dokki, Ayman (2006). The Reality of Total Quality Management in the Ministries of the Palestinian National Authority in the Gaza Strip, unpublished Master Thesis, Faculty of Commerce, Islamic University, Gaza, Palestine.

- EFA, (2005.)"Understanding Education Quality", Global Monitoring Report, USA.

- El Sayed, Yousry Mostafa (2013). Development of Professional Competence of Teachers in

$$
\begin{aligned}
& \text { • وضع خطط منكاملة لنشر ثقافة الجودة في الجامعات } \\
& \text { الفلسطينية واللبنانية من خلال وسائل متعددة كالتدريب، } \\
& \text { والتأهيل، والتعليم. }
\end{aligned}
$$

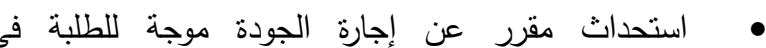

$$
\begin{aligned}
& \text { الجامعات الفلسطينية واللبنانية. }
\end{aligned}
$$

\section{References:}

- Abu Abda, Fatima Issa (2011). The Degree of Application of TQM Standards in Nablus Schools from the Point of View of the Principals. Unpublished Master Thesis in Educational Administration, An-Najah National University: Nablus, Palestine.

- Abu easi, hamdan (2003). Masadir Tamwil Altaelim Altaqanii fi Muhafazat Ghazat Waliat Eamal Muqtarahat Lieilajiha", waraqat eamal muqadimat 'iilaa alhalqat aldirasiat alearabia "aqtisadiaat altaelim altaqni, almuneaqadat fi eaman/ al'urduni min (30/8) 'iilaa (4/9).

- Abu Easi, Hamdan (2003). Mueawiqat Tatwir Altaelim Altaqanii fi Muhafazat Ghazat Waliat Eamal Muqtarahat Lieilajiha, waraqat eamal muqadimat 'iilaa warshat eamal bieunwan " altaelim altaqniu fi filstin/ muhafazat ghazat alwaqie waltmwh" almuneaqadat bikaliat filastin altaqniat - dayr albalah bitarikh (7/5).

- Al-Adadi, Said Ben Ali (2012). The Obstacles of Implementing Total Quality Management in Higher Education Institutions, An Empirical Study in the Arab Journal for Quality Assurance of Higher Education, Volume 5, No. (9).

- Al-Daradkeh, Amjad Mahmoud Mohammed (2004). The Degree of Application of Total Quality Management in Balqa Applied University from the Point of View of Its Educational Leaders. Unpublished Master Thesis in Public Administration, University of Jordan: Amman, Jordan.

- Al-Dhafiri, Mohammed (2011). The Degree of Application of Total Quality Management and Its Relation to Strategic Planning in the Ministry of Education in the State of Kuwait from the Point of View of Administrators. Unpublished Master Thesis in Educational Leadership and Management, Middle East University: Amman, Jordan.

- Al-malah, Muntaha Ahmed Ali (2005). The Degree of Achieving the Standards of Total Quality Management in the Palestinian Universities in the West Bank Governorates as Perceived by Faculty Members. Unpublished MA in Educational Administration, An-Najah National University: Nablus, Palestine. 
Academic Accreditation of Public and University Education Institutions, First Edition, Safaa Publishing House, Amman, Jordan.

- Malhouf, Meshal Mohammed (2007). The Level of Awareness of Educational Leaders to Manage the Total Quality in the Educational Areas in Kuwait, and the degree of their readiness to implement them. Unpublished Master Thesis, Amman Arab University: Amman, Jordan.

- Natour, Rola Mohammed Shafiq Rateb, (2004). Study of the Extent of the Application of Total Quality Management in Government Agencies in Jordan, Master Thesis, University of Jordan, Jordan.

- Nughraha, Paul (2003), Management in Teaching\& Learning Process, (online) Available from: http// www.petra.ac.id/English/ science. (01/02/2019)

- Qashmar, Ali Lutfe (2019). The Role of Professional Ethics in Promoting a Culture of Total Quality in Palestinian Universities from the Perspective of Employees, International Journal of Quality Assurance, Volume II, First Issue, Zarqa University, Jordan.

- Radi, Mervat Mohamed (2006). Obstacles to the Application of Total Quality Management in Technical Education Institutions in the Gaza Governorates and the Methods of Overcoming Them, Unpublished Master Thesis, Faculty of Commerce, Islamic University, Gaza, Palestine.

- Shuailan, Nora Khamis (2007). The Availability of the Principles of Total Quality Management in the Management of Secondary Schools for Girls in Saudi Arabia. Unpublished Master Degree in Education, Gulf University: Bahrain.

- Tamimi, Fawaz Mohammed (2006). The Effectiveness of Using the Quality Management System (ISO) in the Development of Administrative Units in the Ministry of Education in Jordan from the Point of View of Employees and the Degree of Satisfaction with This System. Unpublished $\mathrm{PhD}$ thesis, Amman Arab University: Amman, Jordan.

- Tari, Juan Jose, (2005), Components of Successful Total Quality Management. The TQM Magazine, Vol. 17, No. 2, 2005. pp. $182,194$.

- Tribus, Myron.(2009), Quality in Education According to the Teachings of Deming and Feuerstein, www.fremont. Ça.
How to Prepare Remedial Plans to Improve the Achievement Level of Vulnerable Students, United Arab Emirates University, College of Education, Guidance Center enrollment in Abu Dhabi.

- Ghafri, Saleh bin Said (2004). The Degree of Implementation of TQM in Basic Education Schools in Oman as Perceived by School Principals. Unpublished Master Thesis in Educational Administration, University of Jordan: Amman, Jordan.

- Gouda, Mahfouz Ahmed (2006). Total Quality Management, Rapporteur at Al-Quds Open University, Copyright (C) Al-Quds Open University, Ramallah.

- Hamdan, Abderrahim (2004). The Role of Libraries of Technical Colleges in the Service of Scientific Research in Palestine, the first educational conference entitled "Education in Palestine and the challenges of the times", held at the Islamic University of Gaza, Volume (12), June.

- Hawli, Olayan (2004). The Concept of Quality in Higher Education, Journal of Quality in Education, Volume I, First Issue, August.

- Hernandes, Justo Rolando, Jr (2002) Total Quality Management in Education. The application of TQM in à Texas school district. $\mathrm{Ph}$. D University of Texas at Austin DAL-A 62\11, May, p 36390.

- Kanani, Sabih Karam (2005). The Requirements of the Application of Total Quality Management in the Faculties of Education Ibn al-Haytham and Ibn Rushd at the University of Baghdad, an unpublished master thesis, College of Education Ibn alHaytham, University of Baghdad.

- Khadr, Ghazi Mohammed Ahmad (2004). The Degree of Relevance and Applicability of TQM in UNRWA Schools in Jordan. Unpublished Master Thesis in Educational Administration, University of Jordan: Amman, Jordan.

- Khamisi, Salama (2007). Effective School Quality Standards in the Light of the SystemOriented Approach: A Systematic Vision, Saudi Educational and Psychological Sciences Association, 14th Annual Meeting "Quality in General Education", Qassim, Saudi Arabia.

- Khudair, Inayat Muhammad (2007). "The Reality of Knowledge and Application of Total Quality Management in the Palestinian Directorates of Education from the Viewpoint of its Employees. Unpublished Master Thesis, An-Najah National University: Nablus, Palestine.

- Majeed, Sawsan Shaker and Al-Ziyadat, Mohammad Awwad (2008). Quality and 
الثاملة سعياً نحو التميز (بحث منشور)، المؤتتر

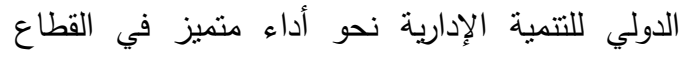
الحكومي، الرياض، المملكة العربية السعودية.

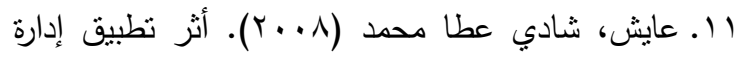
الجودة الثناملة على الأداء المؤسسي. رسالة ماجستير في إدارة الأعمال غير منشورة، الجامعة الإسلامية: غزة، الإناه فلسطين، صبا إنارة الاعنا

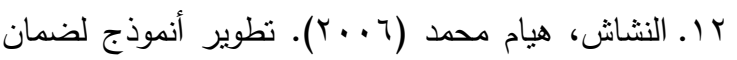

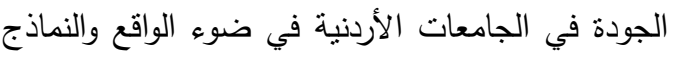
العالمية. أطروحة دكتوراه غير منشورة، جامعة عمان العربية: عمان، الأردن، صهبه.

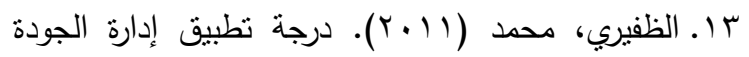
الثناملة وعلاقتها بالتخطيط الاستراتيجي في وزارة التربية في دولة الكويت من وجهة نظر الإداريين. رسالة ماجستير في الإدارة والقيادة التزبوية غير منشورة، جامعة الثرق الأوسط: عمّان، الأردن.

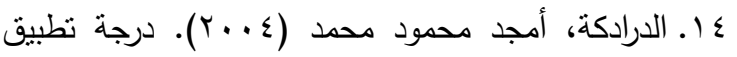
إدارة الجودة الثاملة في جامعة البلقاء النطبيقية من وجهة نظر القادة التزبويين فيها. رسالة ماجستير في الإدارة العامة غير منشورة، الجامعة الأردنية: عمان،

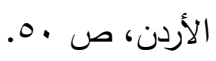

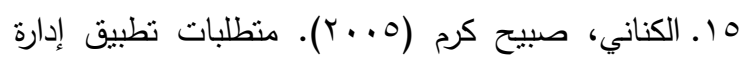
الجودة الثناملة في كليتي التربية ابن الهيثم وابن رشد في جامعة بغداد، رسالة ماجستير غير منشورة، كلية التربية ابن الهيثم، جامعة بغداد، صك ؟ع.

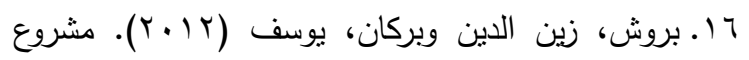
تطبيق نظام ضمان الجودة في مؤسسات التعليم العالي

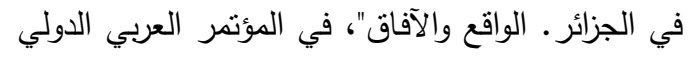
الثاني لضمان جودة التعليم العالي، الجامعة الخليجية،

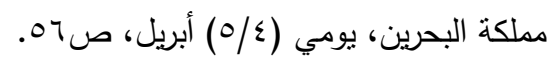

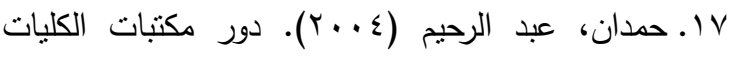

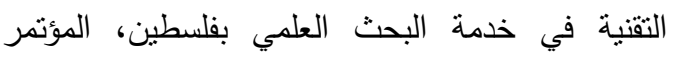
التزبوي الأول بعنوان "التربية في فلسطين وتحديات العصر"، المنعقد بالجامعة الإسلامية بغزة، المجلد

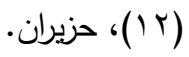

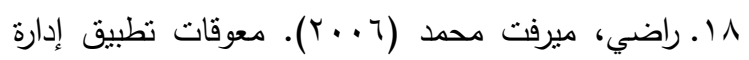
الجودة الثناملة في مؤسسات التعليم التقني في محافظات غزة وسبل التغلب عليها، رسالة ماجستير غير منشورة، كلية التجارة، الجامعة الإسلامية، غزة، فلسطين.

\section{الهوامش:}

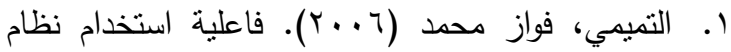
إدارة الجودة (آيزو) في تطوير الوحدات الإدارية في وزارة التربية والتعليم في الأردن من وجهة نظر العاملين العزين فيها ودرجة رضاهم عن هذا النظام. أطروحة دكتوراه غير منشورة، جامعة عمان العربية: عمان، الأردن.

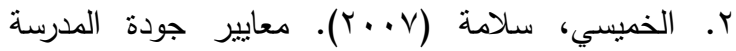
الفعالة في ضوء منحى النظم: رؤية منهجية، الجمعية

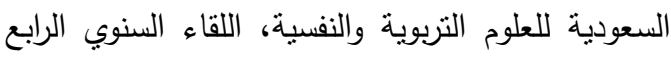
عثر "الجودة في التعليم العام"، القصيم، المملكة العربية

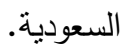

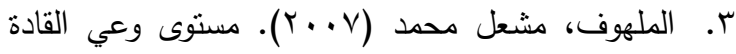
التربويين لإدارة الجودة الثناملة في المناطق التعليمية بالكويت، ودرجة استعدادهم لتطبيقها. رسالة ماجستير غير منشورة، جامعة عمان العربية: عمان، الأردن.

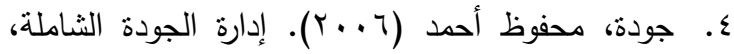
مقرر في جامعة القس المفتوحة، حقوق الطبع والنشر محفوظة لجامعة القس المفتوحة، رام الله.

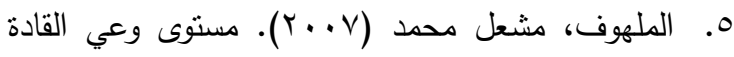
التربوبين لإدارة الجودة الثاملة في المناطق التعليمية بالكويت، ودرجة استعدادهم لتطبيقها. رسالة ماجسنير غير منشورة، جامعة عمان العربية: عمان، الأردن.

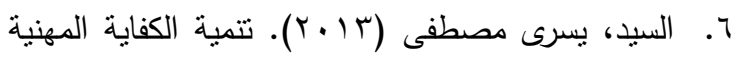
للمعلمات في كيفية إعداد الخطط العلاجية لتحسين

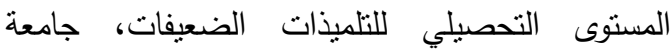
الامارات العربية المتحدة، كلية التربية، مركز الاتنساب الموجه بأبوظبي.

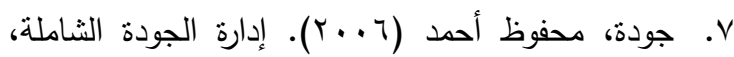
مقرر في جامعة القس المفتوحة، حقوق الطبع والنشر محفوظة لجامعة القس المفتوحة، رام الله.

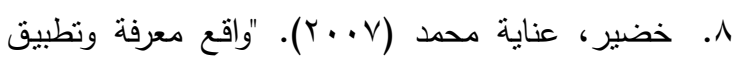
إدارة الجودة الثناملة في مديريات التربية والتعليم الفلسطينية من وجهة نظر العاملين فيها. رسالة ماجستير غير منشورة، جامعة النجاح الوطنية: نابلس، فلسطين.

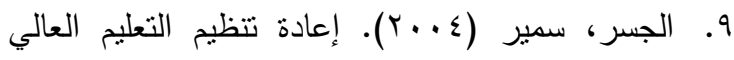
الخاص، ورقة عمل مقدمة لورشة في وزارة التربية والتعليم العالي، المديرية العامة للتعليم العالي، بيروت، لبنان، في الفترة (• (1-ع ؟) شباط.

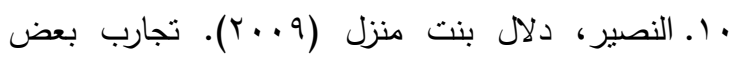
الجامعات العالمية والعربية والمحلية في تطبيق الجودة 


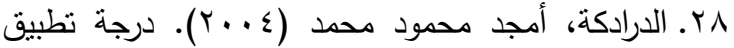

إدارة الجودة الثاملة في جامعة البلقاء النطبيقية من

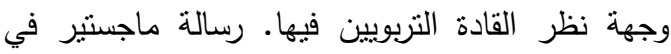

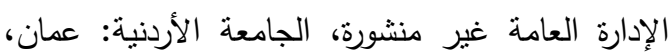

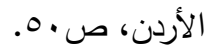

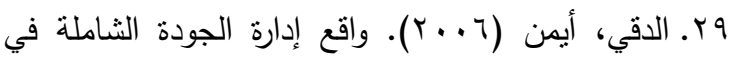
وزارات السلطة الوطنية الفلسطينية في قطاع غزة، رسالة ماجستير غير منشورة، كلية التجارة، الجامعة الإسلامية، غزة، فلسطين.

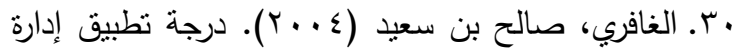
الجودة الثاملة في مدارس التعليم الأساسي بسلطنة

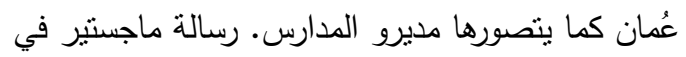

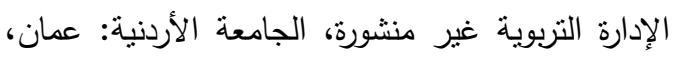

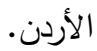

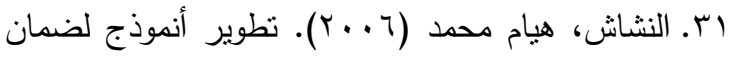

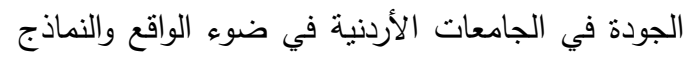
العالمية. أطروحة دكتوراه غير منشورة، جامعة عمان

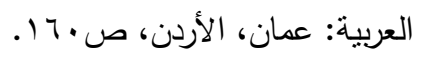

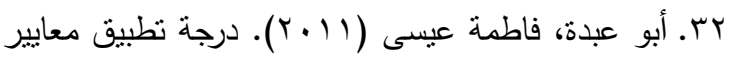

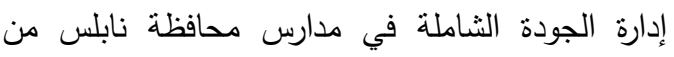
وجهة نظر الدديرين فيها. رسالة ماجستير في الإدارة

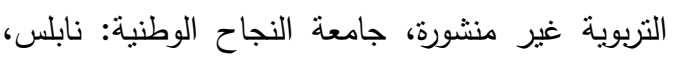
فلسطين.

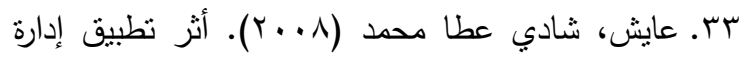
الجودة الثاملة على الأداء المؤسسي. رسالة ماجستير

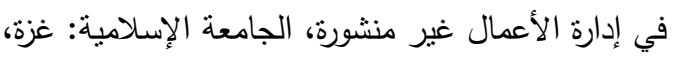

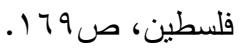

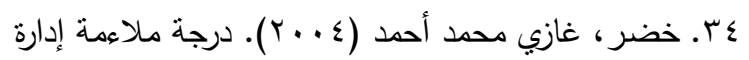
الجودة الثاملة وإمكانية تطبيقها في مدارس وكالة الغوث الدولية في الأردن. رسالة ماجستير في الإدارة التربوية فئية غير منشورة، الجامعة الأردنية: عمان، الأردن.

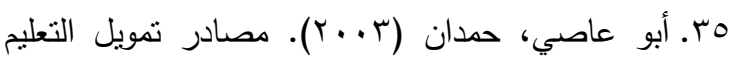
التقني في محافظات غزة وآليات عمل مقترحة لعلاجها"، ورقة عمل مقدمة إلى الحلقة الدراسية العربية "|(قتصاديات

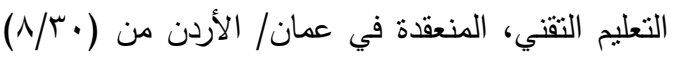

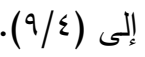
بr. قشمر، علي لطفي (19 (r). دور الأخلاق المهنية في

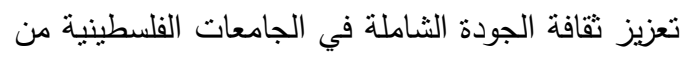

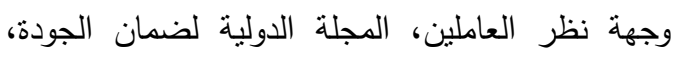
المجلد الثاني، العدد الأول، جامعة الزرقاء، الأردن.

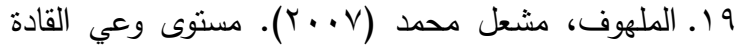
التربويين لإدارة الجودة الثاملة في المناطق التعليمية بالكويت، ودرجة استعدادهم لنطبيقها. رسالة ماجستير

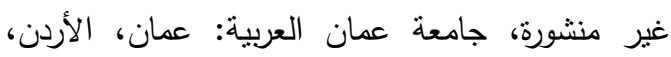
ص ص 7.

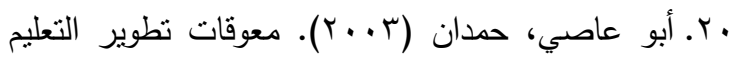
الثقني في محافظات غزة وآليات عمل مقترحة لعلاجها، ورقة عمل مقدمة إلى ورشة عمل بعنوان " التعليم التقني في فلسطين/ محافظات غزة - الواقع والطموح" المنعقدة

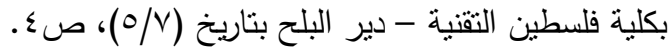

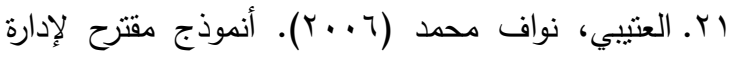
الجودة الثشاملة في جامعة الكويت في ضوء تصني تصورات القيادات وأعضاء هيئة التدريس لإمكانية نطبيقها. أطروحة دكتوراه غير منشورة، جامعة عمان العربية:

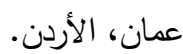

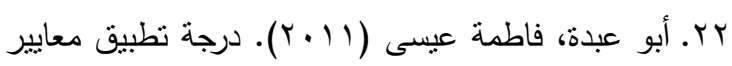

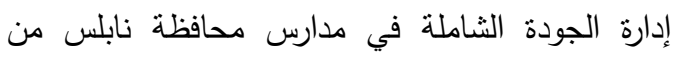
وجهة نظر المديرين فيها. رسالة ماجستير في الإدارة التربوية غير منشورة، جامعة النجاح الوطنية: نابلس،

$$
\text { فلسطين، صبr. }
$$

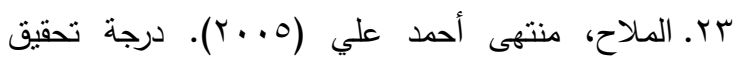
معايير إدارة الجودة الثاملة في الجامعات الفلسطينية في محافظات الضفة الغربية كما يراها أعضاء هيئة التدريس. دراسة ماجستير في الإدارة التزبوية غير لناهية منشورة، جامعة النجاح الوطنية: نابلس، فلسطين،

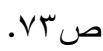

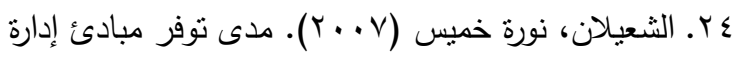
الجودة الثاملة في إدارة المدارس الثانوية للبنات بالمملكة العربية السعودية. رسالة ماجستير في التربية غير الدرد

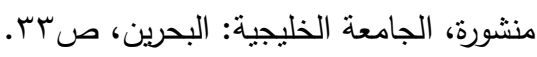

25. Tribus, Myron,) 2009(, Quality in Education According to the Teachings of Deming and Feuerstein, www.fremont. Ça, p63.

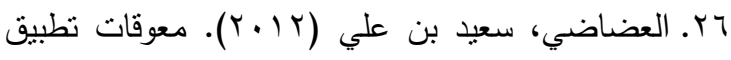
إدارة الجودة الثاملة في مؤسسات التعليم العالي، دراسة ميدانية، في المجلة العربية لضمان جودة التعليم

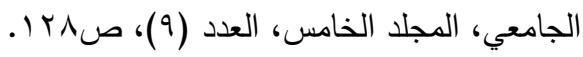

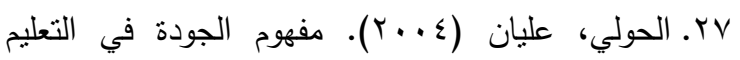

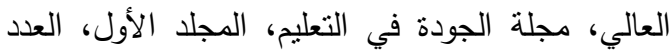

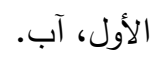




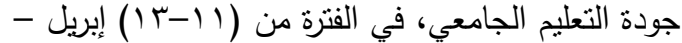
جامعة البحرين: كلية النتربية.

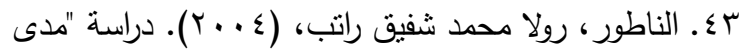

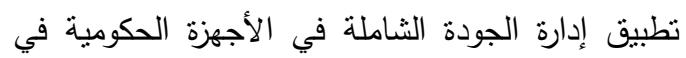
الأردن، رسالة ماجستير، الجامعة الأردنية، الأردن.

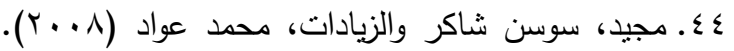
الجودة والاعتماد الأكاديمي لمؤسسات التعليم العام

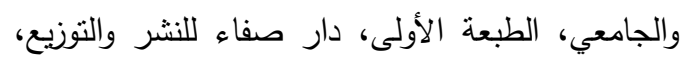

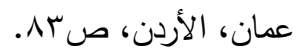

45. Nughraha, Paul (2003), Management in Teaching \& Learning Process, (online) Available from: http/l www.petra.ac.id/English/ science, p7.

46. Tari, Juan Jose, (2005), Components of Successful Total Quality Management. The TQM Magazine, Vol. 17, No. 2, 2005. pp. 182,194.

47. Cronesky, Robert, ET. Al., (2003), Iimplementing Total Quality Management in Higher Education, St. Edward's University, USA, p70.

48. EFA, (2005). "Understanding Education Quality", Global Monitoring Report, USA, p34.

49. Tribus, Myron,(2009). Quality in Education According to the Teachings of Deming and Feuerstein, www.fremont. Ça, p63.

50. Cronesky, Robert, ET. Al., (2003), Implementing Total Quality Management in Higher Education, St. Edward's University, USA.

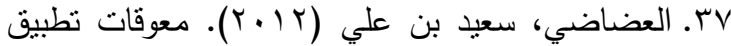

إدارة الجودة الثاملة في مؤسسات التعليم العالي، دراسة

ميدانية، في المجلة العربية لضمان جودة التعليم

الجامعي، الدجلد الخامس، العدد (9).

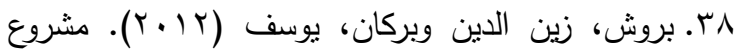

تطبيق نظام ضمان الجودة في مؤسسات التعليم العالي

في الجزائر. الواقع والآفاق"، في المؤتمر العربي الدولي

الثاني لضمان جودة التعليم العالي، الجامعة الخليجية، مملكة البحرين، يومي (ع/ه) أبريل.

9ץ. الظفيري، محمد (1) (1). درجة تطبيق إدارة الجودة

الثناملة وعلاقتها بالتخطيط الاستراتيجي في وزارة التربية

في دولة الكويت من وجهة نظر الإداريين. رسالة

ماجستير في الإدارة والقيادة التزبوية غير منشورة، جامعة الشرق الأوسط: عمّان، الأردن.

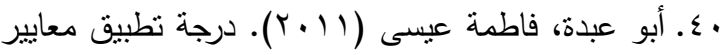

إدارة الجودة الثاملة في مدارس محافظة نابلس من

وجهة نظر المديرين فيها. رسالة ماجستير في الإدارة

التربوية غير منشورة، جامعة النجاح الوطنية: نابلس، فلسطين.

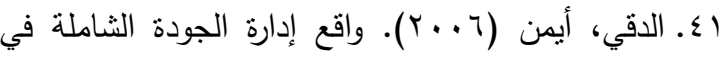

وزارات السلطة الوطنية الفلسطينية في قطاع غزة، رسالة

ماجستير غير منشورة، كلية التجارة، الجامعة الإسلامية، غزة، فلسطين.

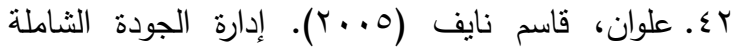

وإمكانية تطبيقها في التحدي، المؤتمر التزبوي الخامس: 